NBER WORKING PAPER SERIES

\title{
WHAT GOODS DO COUNTRIES TRADE? A QUANTITATIVE EXPLORATION OF RICARDO'S IDEAS
}

\author{
Arnaud Costinot \\ Dave Donaldson \\ Ivana Komunjer \\ Working Paper 16262 \\ http://www.nber.org/papers/w16262
}

\author{
NATIONAL BUREAU OF ECONOMIC RESEARCH \\ 1050 Massachusetts Avenue \\ Cambridge, MA 02138 \\ August 2010
}

We thank Gene Grossman, Gordon Hanson, Giovanni Maggi, Jim Rauch, Stephen Redding, Frédéric Robert-Nicoud, Bob Staiger, Kjetil Storesletten, Jonathan Vogel, Kei-Mu Yi, three anonymous referees, and seminar participants at many institutions for very helpful comments. We also thank Don Davis and Sam Kortum for stimulating discussions and precious advice at the Princeton IES Summer Workshop. Nadege Plesier provided excellent research assistance. This paper is a heavily revised version of the 2007 NBER working paper "What Goods Do Countries Trade? New Ricardian Predictions". The views expressed herein are those of the authors and do not necessarily reflect the views of the National Bureau of Economic Research.

NBER working papers are circulated for discussion and comment purposes. They have not been peerreviewed or been subject to the review by the NBER Board of Directors that accompanies official NBER publications.

(C) 2010 by Arnaud Costinot, Dave Donaldson, and Ivana Komunjer. All rights reserved. Short sections of text, not to exceed two paragraphs, may be quoted without explicit permission provided that full credit, including $\odot$ notice, is given to the source. 
What Goods Do Countries Trade? A Quantitative Exploration of Ricardo's Ideas

Arnaud Costinot, Dave Donaldson, and Ivana Komunjer

NBER Working Paper No. 16262

August 2010

JEL No. F10,F11

\begin{abstract}
$\underline{\text { ABSTRACT }}$
The Ricardian model predicts that countries should produce and export relatively more in industries in which they are relatively more productive. Though one of the most celebrated insights in the theory of international trade, this prediction has received virtually no attention in the empirical literature since the mid-sixties. The main reason behind this lack of popularity is the absence of clear theoretical foundations to guide the empirical analysis. Building on the seminal work of Eaton and Kortum (2002), the present paper offers such foundations and uses them to quantify the importance of Ricardian comparative advantage. Using trade and productivity data from 1997, we estimate that, ceteris paribus, the elasticity of bilateral exports with respect to observed productivity is 6.53. From a welfare standpoint, however, the removal of Ricardian comparative advantage at the industry level would only lead, on average, to a $5.5 \%$ decrease in the total gains from trade.
\end{abstract}

Arnaud Costinot

Department of Economics

MIT, E52-243B

50 Memorial Drive

Cambridge MA 02142-1347

and NBER

costinot@mit.edu

Dave Donaldson

MIT Department of Economics

50 Memorial Drive, E52-243G

Cambridge, MA 02142-1347

and NBER

ddonald@mit.edu
Ivana Komunjer

Department of Economics

University of California, San Diego

9500 Gilman Drive

La Jolla, CA 92093-0508

komunjer@ucsd.edu 


\section{INTRODUCTION}

The Ricardian model predicts that countries should produce and export relatively more in industries in which they are relatively more productive. Though one of the most celebrated insights in the theory of international trade, this prediction has received virtually no attention in the empirical literature since the mid-sixties; see e.g. MacDougall (1951), Stern (1962), and Balassa (1963). ${ }^{1}$ The main reason behind this lack of popularity is not the existence of strong beliefs regarding the (un)importance of technological considerations. It derives instead from the absence of any clear theoretical foundations to guide the empirical analysis; see e.g. Bhagwati (1964), Deardorff (1984), and Leamer and Levinsohn (1995). Building on the seminal work of Eaton and Kortum (2002), this paper develops such foundations and uses them to quantify the importance of Ricardian comparative advantage at the industry level. $^{2}$

The tight connection between theory and empirics offered by our paper has two crucial advantages over the previous literature. First, when estimating the importance of Ricardian comparative advantage in the cross-section, we do not have to rely on ad-hoc measures of export performance such as total exports towards the rest of the world (MacDougall, 1951; Stern, 1962); total exports to third markets (Balassa, 1963); or bilateral net exports (Golub and Hsieh, 2000). Our theory tells us exactly what the dependent variable in our crosssectional regressions ought to be: log of exports, disaggregated by exporting and importing countries, differenced across industries and exporters, and adjusted for differences in levels of 'openness' to account for trade-driven selection. Using trade and productivity data, we can therefore offer the first theoretically consistent Ricardian test. Our preferred estimate implies that, ceteris paribus, the elasticity of (adjusted) bilateral exports with respect to observed productivity is positive, as our Ricardian model predicts, and equal to 6.53.

Second, our clear theoretical foundations allow us to do general equilibrium counterfactual analysis. In order to quantify further the importance of Ricardian comparative advantage, we then ask: What if, for any pair of exporters, there were no relative productivity differences

\footnotetext{
${ }^{1}$ A notable exception, which we discuss more below, is Golub and Hsieh (2000).

${ }^{2}$ This quantification depends on the level of aggregation at which an 'industry' is defined. Throughout this paper, industries will be defined as the lowest level of disaggregation for which we have productivity data that are comparable across countries and industries, namely the two-digit ISIC level.
} 
across industries? What would be the consequences for aggregate trade flows and welfare? According to our estimates, the removal of Ricardian comparative advantage at the industry level would only lead, on average, to a $5.5 \%$ decrease in the total gains from trade.

Section 2 describes our theoretical framework. We consider an economy with multiple countries, multiple industries, and one factor of production, labor. Up to this point, this is a standard Ricardian model. We generalize this model by allowing for intra-industry heterogeneity à la Eaton and Kortum (2002). Formally, we assume that each good is available in many varieties and that labor productivity differs across varieties. The key feature of this model is that labor productivity may be separated into: ( $i)$ a deterministic component, which is country and industry specific; and (ii), a stochastic component, randomly drawn across countries, industries, and varieties. The former, which we refer to as 'fundamental productivity,' captures factors such as climate, infrastructure, and institutions that affect the productivity of all producers in a given country and industry. ${ }^{3}$ The latter, by contrast, reflects idiosyncratic differences in technological know-how across varieties.

Section 3 derives our theoretical predictions, relates them to the previous Ricardian literature, and investigates their robustness. The first set of predictions are cross-sectional in nature, and describe how productivity differences affect trade patterns across countries and industries in any trading equilibrium. A key result that emerges is a parsimonious method for correcting for the trade-driven selection that creates an endogenous wedge between fundamental and observed productivity. The second set of predictions concerns general equilibrium responses to novel and natural counterfactual scenarios that explore by how much aggregate trade flows and welfare would change if, for any pair of exporters, there were no fundamental relative productivity differences across industries.

Section 4 tests our cross-sectional predictions using the best available data on internationallycomparable productivity and trade flows across countries and industries. In line with our Ricardian model, our measures of relative productivity are computed using relative producer prices from the GGDC Productivity Level Database. Our analysis illustrates how tests of the Ricardian model, which have long been perceived as hopelessly ad-hoc, can be performed

\footnotetext{
${ }^{3}$ Matsuyama (2005), Acemoglu, Antras, and Helpman (2007), Levchenko (2007), Vogel (2007), Costinot (2009), and Cuñat and Melitz (2010) explicitly model the impact of various institutional features - e.g. labor market flexibility, the quality of contract enforcement, or credit market imperfections - on labor productivity across countries and industries.
} 
in a theoretically consistent manner. This procedure allows us to estimate the extent ' $\theta$ ' of intra-industry heterogeneity which is the key structural parameter governing the relationship between productivity and exports in this Ricardian world. After adjusting for differences in openness across exporting countries and industries, which turns out to be empirically important, our preferred estimate of $\theta$ is equal to 6.53. This is in line with previous estimates of $\theta$ obtained by researchers using different methodologies; see e.g. Eaton and Kortum (2002), Bernard, Eaton, Jensen, and Kortum (2003), Donaldson (2008), and Simonovska and Waugh (2009).

Section 5 presents our counterfactual results. Using productivity measures revealed by our Ricardian model to minimize measurement error, we investigate the consequences for aggregate trade flows and welfare of removing relative productivity differences across countries and industries. According to our estimates, the removal of Ricardian comparative advantage at the industry level would only lead, on average across countries, to a $5.5 \%$ decrease in the total gains from trade. We conclude Section 5 by exploring how the magnitude of this estimate is related to two important features of the data: heterogeneous preferences and heterogeneous trade costs. Both of these aspects of heterogeneity tend to offset the purely productivity-driven heterogeneity that is at the heart of the Ricardian model.

Our paper is related both to the early empirical tests of the Ricardian model-MacDougall (1951), Stern (1962), and Balassa (1963) — and to a much more recent but rapidly growing literature based on multi-sector extensions of the Eaton and Kortum (2002) model-Shikher (2004, 2008), Costinot (2005), Chor (2008), Donaldson (2008), Caliendo and Parro (2009), Kerr (2009), and Burstein and Vogel (2010). Relative to this literature, our first contribution is to show how micro-foundations à la Eaton and Kortum (2002) can be used to contrast the cross-sectional predictions of the Ricardian model with the data. Using our model, we estimate the impact of observed productivity differences on the pattern of trade across countries and industries without having to rely on ad-hoc measures of export performance, bilateral comparisons inspired by a two-country model, or unclear orthogonality conditions. ${ }^{4}$ Our second contribution is to show how estimates obtained from these regressions can be used

\footnotetext{
${ }^{4}$ It is worth emphasizing that, our theoretical foundations notwithstanding, our cross-sectional results are much closer, in spirit, to those of MacDougall (1951), Stern (1962), Balassa (1963), and Golub and Hsieh (2000) than to those of Eaton and Kortum (2002). Fundamentally, the focus of our analysis is the commodity pattern of trade, not the total volume of trade. Compared to Eaton and Kortum (2002), our
} 
to measure, in a well-defined way, the welfare impact of Ricardian comparative advantage at the industry level. ${ }^{5}$ Put together, these cross-sectional and counterfactual results provide a complete exploration of the quantitative implications of Ricardo's ideas.

Our analysis is also related, though less closely, to a large empirical literature investigating the role of various sources of comparative advantage; see e.g. Harrigan (1997b), Beck (2003), Romalis (2004), Yeaple and Golub (2007), Nunn (2007), Manova (2008), and Morrow (2009). Like the previous papers, we analyze how differences in costs of production may affect the pattern of trade across countries and industries. However, our main focus is not to assess which particular channel-e.g. institutions, infrastructure, or factor endowments - contributes more to the cross-sectional variation in costs of production, and in turn, bilateral trade flows. Like in previous Ricardian tests, we start by interpreting the cross-sectional variation in costs of production as the result of fundamental productivity differences. Conditional on this interpretation, we then investigate how much of the cross-sectional variation in trade flows and the overall gains from trade can be explained by these differences. In other words, the goal of the present paper is not to investigate what causes observed productivity differences or whether such differences may be accounted for by differences in factor endowments. ${ }^{6}$ Our goal simply is to ask: Seen through the lens of the Ricardian model, how important are productivity differences across countries and industries?

\section{Theoretical Framework}

We consider a world economy comprising $i=1, \ldots, I$ countries and one factor of production, labor. There are $k=1, \ldots, K$ industries or goods and constant returns to scale in the production of each good. Labor is perfectly mobile across industries and immobile across countries. We denote by $L_{i}$ and $\mathrm{w}_{i}$ the number of workers and the wage in country $i$,

empirical exercise therefore requires independent measures of productivity as well as trade data disaggregated by industry.

${ }^{5}$ In this regard, the present analysis is most closely related to Chor (2008) who compares the impact of various sources of comparative advantage on welfare, albeit not in a fully structural way.

${ }^{6}$ While an assessment of the relative importance of productivity and factor endowment differences for the determinants of comparative advantages is not our main focus, we do present, in Section 4.3 below, evidence that our estimates are robust to controlling for factor price and factor intensity differences. 
respectively. Up to this point, this is a standard Ricardian model. We generalize this model by allowing for intra-industry heterogeneity in labor productivity.

Technology. Each good $k$ may come in an infinite number of varieties indexed by $\omega \in \Omega \equiv$ $\{1, \ldots,+\infty\} .^{7}$ We denote by $z_{i}^{k}(\omega)$ the number of units of the $\omega$ th variety of good $k$ that can be produced with one unit of labor in country $i$. Following Eaton and Kortum (2002), we assume that:

A1. For all countries $i$, goods $k$, and their varieties $\omega, z_{i}^{k}(\omega)$ is a random variable drawn independently for each triplet $(i, k, \omega)$ from a Fréchet distribution $F_{i}^{k}(\cdot)$ such that:

$$
F_{i}^{k}(z)=\exp \left[-\left(z / z_{i}^{k}\right)^{-\theta}\right] \text {, for all } z \geq 0
$$

where $z_{i}^{k}>0$ and $\theta>1$.

According to Assumption A1, technological differences across countries and industries only depend on two parameters, $z_{i}^{k}$ and $\theta .{ }^{8}$ We refer to $z_{i}^{k}$ as the fundamental productivity of country $i$ in industry $k$. It aims to capture factors such as climate, infrastructure, and institutions that affect the productivity of all producers in a given country and industry. For each industry $k$, the cross-country variation in $z_{i}^{k}$ s pins down the cross-country variation in relative labor productivity at the core of the standard Ricardian model. Formally, Equation (1) implies $z_{i}^{k} / z_{i^{\prime}}^{k}=E\left[z_{i}^{k}(\omega)\right] / E\left[z_{i^{\prime}}^{k}(\omega)\right]$, for any $i, i^{\prime}$, and $k$.

By contrast, the second parameter, $\theta$, measures intra-industry heterogeneity. It aims to reflect the scope for idiosyncratic differences in technological know-how across varieties, which we assume to be the same in all countries and industries. ${ }^{9}$ In this model $\theta$ parametrizes

\footnotetext{
${ }^{7}$ Alternatively, we could have assumed the existence of a continuum of varieties. By assuming that the number of varieties is infinite, but countable, we avoid the technical difficulties of invoking the law of large numbers with a continuum of i.i.d. variables; see e.g. Al-Najjar (2004). Nothing substantial hinges on this particular modeling choice. More economically substantial is the implicit assumption that the number of varieties per industry - unlike in a monopolistically competitive model with free entry - is exogenously given.

${ }^{8}$ Section 3.4 analyzes how our results extend to environments in which A1 is not satisfied.

${ }^{9}$ Using a unique dataset that documents physical output (rather than just revenue) at the plant level in the United States, Foster, Haltiwanger, and Syverson (2008) document significant intra-industry heterogeneity in plant-level physical productivity.
} 
the impact of changes in fundamental productivity levels, $z_{i}^{k}$, on aggregate trade flows. Estimating $\theta$ will be one key focus of our quantitative exploration of the Ricardian model.

Trade costs. Trade frictions take the form of 'iceberg' trade costs. Formally, we assume that:

A2. For each unit of good $k$ shipped from country $i$ to country $j$, only $1 / d_{i j}^{k} \leq 1$ units arrive, with $d_{i j}^{k}$ such that: $(i) d_{i i}^{k}=1$; and $(i i) d_{i l}^{k} \leq d_{i j}^{k} \cdot d_{j l}^{k}$ for any third country $l$.

The second part of Assumption A2 simply rules out cross-country arbitrage opportunities.

Market structure. Markets are assumed to be perfectly competitive. Together with constant returns to scale in production, perfect competition implies:

A3. In any country $j$, the price $p_{j}^{k}(\omega)$ paid by buyers of variety $\omega$ of good $k$ is

$$
p_{j}^{k}(\omega)=\min _{1 \leq i \leq I}\left[c_{i j}^{k}(\omega)\right]
$$

where $c_{i j}^{k}(\omega)=\left(d_{i j}^{k} \cdot \mathrm{w}_{i}\right) / z_{i}^{k}(\omega)$ is the cost of producing and delivering one unit of this variety from country $i$ to country $j$.

For each variety $\omega$ of good $k$, buyers in country $j$ are 'shopping around the world' for the best price available. In what follows, we let $c_{i j}^{k}=\left(d_{i j}^{k} \cdot \mathrm{w}_{i}\right) / z_{i}^{k}>0$.

Preferences. In each country there is a representative consumer with a two-level utility function. The upper tier utility function is Cobb-Douglas, while the lower tier is CES. ${ }^{10}$ Accordingly, expenditures are such that:

A4. In any country $j$, total expenditure on variety $\omega$ of good $k$ is

$$
x_{j}^{k}(\omega)=\left[p_{j}^{k}(\omega) / p_{j}^{k}\right]^{1-\sigma_{j}^{k}} \cdot \alpha_{j}^{k} \mathrm{w}_{j} L_{j},
$$

where $0 \leq \alpha_{j}^{k} \leq 1, \sigma_{j}^{k}<1+\theta$, and $p_{j}^{k} \equiv\left[\sum_{\omega^{\prime} \in \Omega} p_{j}^{k}\left(\omega^{\prime}\right)^{1-\sigma_{j}^{k}}\right]^{1 /\left(1-\sigma_{j}^{k}\right)}$.

The above expenditure function is a standard feature of models of intra-industry trade in the 'new trade' literature; see e.g. Helpman and Krugman (1985). The first preference parameter, $\alpha_{j}^{k}$, measures the share of expenditure on varieties from industry $k$ in country $j$,

\footnotetext{
${ }^{10}$ While the Cobb-Douglas assumption in A4 could be dispensed with in favor of any upper tier utility function for our cross-sectional results, it will play a non-trivial role in our counterfactual analysis.
} 
whereas the second, $\sigma_{j}^{k}$, is the elasticity of substitution between varieties. The restriction $\sigma_{j}^{k}<1+\theta$ is a technical assumption that guarantees the existence of a well defined CES price index, $p_{j}^{k}$, in country $j$ and industry $k$. It is worth emphasizing that demand conditions may vary across countries and industries: $\alpha_{j}^{k}$ and $\sigma_{j}^{k}$ are functions of $j$ and $k$. For future reference, we denote by $p_{j} \equiv \prod_{k=1}^{K}\left(p_{j}^{k}\right)^{\alpha_{j}^{k}}$ the consumer price index in country $j$.

Trade Balance. We denote by $x_{i j}^{k} \equiv \sum_{\omega \in \Omega_{i j}^{k}} x_{j}^{k}(\omega)$ the value of total exports from country $i$ to country $j$ in industry $k$, where $\Omega_{i j}^{k} \equiv\left\{\omega \in \Omega \mid c_{i j}^{k}(\omega)=\min _{1 \leq i^{\prime} \leq I} c_{i^{\prime} j}^{k}(\omega)\right\}$ is the set of varieties exported by country $i$ to country $j$ in industry $k$. Similarly, we denote by $\pi_{i j}^{k} \equiv x_{i j}^{k} / \sum_{i^{\prime}=1}^{I} x_{i^{\prime} j}^{k}$ the share of exports from country $i$ in country $j$ an industry $k$. Our final assumption is that:

A5. For any country $i$, trade is balanced

$$
\sum_{j=1}^{I} \sum_{k=1}^{K} \pi_{i j}^{k} \alpha_{j}^{k} \gamma_{j}=\gamma_{i}
$$

where $\gamma_{i} \equiv \mathrm{w}_{i} L_{i} / \sum_{i^{\prime}=1}^{I} \mathrm{w}_{i^{\prime}} L_{i^{\prime}}$ is the share of country $i$ in world income.

Conditional on aggregate trade flows, Assumption A5 pins down relative wages, $\mathrm{w}_{i} / \mathrm{w}_{i^{\prime}}$, around the world. ${ }^{11}$ This completes our description of a trade equilibrium in this economy.

\section{Theoretical Predictions}

Using the previous theoretical framework, Assumptions A1-A5, we derive two types of predictions. First, we show how differences in labor productivity across countries and industries affect the pattern of trade in a given equilibrium. These cross-sectional predictions will form the basis of our first empirical exercises (in Section 4), the goal of which is to estimate the key model parameter $\theta$ which governs the relationship between productivity and exports in this Ricardian world. Second, we demonstrate how changes in labor productivity would affect trade and welfare across equilibria. These counterfactual predictions will form the basis of our final empirical exercise (in Section 5), in which we explore the importance of inter-industry Ricardian forces for generating gains from trade around the world.

\footnotetext{
${ }^{11}$ For expositional purposes, we have chosen to impose trade balance, but it should be clear that all our results would hold if we had assumed fixed trade imbalances instead. It should also be clear that, like the Cobb-Douglas preferences in A4, A5 could be dispensed with for our cross-sectional results.
} 
3.1. Productivity and Trade: A First Look. Before deriving our new cross-sectional predictions, we first describe the impact of fundamental productivity and trade costs on bilateral exports at the industry level. By themselves, such theoretical results are of limited use for empirical work because fundamental productivity levels cannot be observed: doing so would require data on products that have been driven out of domestic production by the forces of trade. This intermediate step, however, will allow us to compare our approach to the previous theoretical literature on the Ricardian model - a literature without clear predictions in a world with many countries and industries - in a transparent manner. In the next subsection, we will then highlight how trade-driven selection drives a wedge between fundamental productivity and observed productivity, and how empirical work can nevertheless proceed in the face of this wedge.

Lemma 1. Suppose that Assumptions A1-A4 hold. Then for any importer, $j$, any pair of exporters, $i$ and $i^{\prime}$, and any pair of goods, $k$ and $k^{\prime}$,

$$
\ln \left(\frac{x_{i j}^{k} x_{i^{\prime} j}^{k^{\prime}}}{x_{i j}^{k^{\prime}} x_{i^{\prime} j}^{k}}\right)=\theta \ln \left(\frac{z_{i}^{k} z_{i^{\prime}}^{k^{\prime}}}{z_{i}^{k^{\prime}} z_{i^{\prime}}^{k}}\right)-\theta \ln \left(\frac{d_{i j}^{k} d_{i^{\prime} j}^{k^{\prime}}}{d_{i j}^{k^{\prime}} d_{i^{\prime} j}^{k}}\right) .
$$

The proof of Lemma 1 is simple. ${ }^{12}$ Under Assumptions A1-A4, bilateral exports from country $i$ to country $j$ in sector $k$ can be expressed as:

$$
x_{i j}^{k}=\frac{\left(\mathrm{w}_{i} d_{i j}^{k} / z_{i}^{k}\right)^{-\theta}}{\sum_{i^{\prime}=1}^{I}\left(\mathrm{w}_{i^{\prime}} d_{i^{\prime} j}^{k} / z_{i^{\prime}}^{k}\right)^{-\theta}} \cdot \alpha_{j}^{k} \mathrm{w}_{j} L_{j} .
$$

To go from this expression to Equation (5), we then use a simple 'difference-in-difference' strategy. The first (log-) difference, $x_{i j}^{k} / x_{i j}^{k^{\prime}}$, allows us to control for differences in wages, $\mathrm{w}_{i}$, across exporters, as well as differences in income, $\mathrm{w}_{j} L_{j}$, across importers. The second (log-) difference, $\left(x_{i j}^{k} / x_{i j}^{k^{\prime}}\right) /\left(x_{i^{\prime} j}^{k} / x_{i^{\prime} j}^{k^{\prime}}\right)$, allows us to control for differences in the share of expenditure, $\alpha_{j}^{k}$, across sectors. Equation (5) follows.

At this point, our theoretical framework imposes very little structure on the variation of trade costs. To better relate Lemma 1 to previous results in the literature, it is useful to consider briefly the special case in which:

$$
d_{i j}^{k}=d_{i j} \cdot d_{j}^{k} \text { for all } k \text { and } i \neq j \text {. }
$$

\footnotetext{
${ }^{12}$ Proofs of all our formal results can be found in Appendix A.
} 
This restriction is trivially satisfied, for example, in Dornbusch, Fischer, and Samuelson (1977) who assume that trade costs are symmetric across countries and identical across goods, $d_{i j}^{k}=d_{j i}^{k} \equiv d$. In Equation (7), the first parameter $d_{i j}$ measures the trade barriers which are specific to countries $i$ and $j$ such as physical distance, existence of colonial ties, use of a common language, or participation in a monetary union. The second parameter $d_{j}^{k}$ measures the policy barriers imposed by country $j$ on good $k$, such as import tariffs and standards, which, in line with 'the most-favored-nation' clause of the World Trade Organization, may not vary by country of origin. ${ }^{13}$

In this special case, since $d_{i j}^{k} d_{i^{\prime} j}^{k^{\prime}} / d_{i j}^{k^{\prime}} d_{i^{\prime} j}^{k}=1$ for all $i, i^{\prime} \neq j$, Lemma 1 directly implies:

Corollary 2. Suppose that Assumptions A1-A4 and Equation (7) hold. Then for any importer, $j$, and any pair of exporters, $i, i^{\prime} \neq j$, the ranking of relative fundamental productivity determines the ranking of relative exports:

$$
\frac{z_{i}^{1}}{z_{i^{\prime}}^{1}} \leq \ldots \leq \frac{z_{i}^{K}}{z_{i^{\prime}}^{K}} \Leftrightarrow \frac{x_{i j}^{1}}{x_{i^{\prime} j}^{1}} \leq \ldots \leq \frac{x_{i j}^{K}}{x_{i^{\prime} j}^{K}} .
$$

Note that, without loss of generality, we can always fix a pair of countries, $i_{1}$ and $i_{2}$, and index the $K$ goods so that:

$$
\frac{z_{i_{1}}^{1}}{z_{i_{2}}^{1}} \leq \ldots \leq \frac{z_{i_{1}}^{K}}{z_{i_{2}}^{K}}
$$

Ranking (8) is at the heart of the standard two-country Ricardian model; see e.g. Dornbusch, Fischer, and Samuelson (1977). When there is no intra-industry heterogeneity, Ranking (8) merely states that country $i_{1}$ has a comparative advantage in (all varieties of) the high $k$ goods. If there only are two countries, the pattern of trade follows: $i_{1}$ produces and exports the high $k$ goods, while $i_{2}$ produces and exports the low $k$ goods. If there are more than two countries, however, the pattern of pairwise comparative advantage no longer determines the pattern of trade. In this case, the standard Ricardian model loses most of its intuitive content; see e.g. Jones (1961) and Wilson (1980).

\footnotetext{
${ }^{13}$ In practice, Equation (7) may be violated because of preferential trade agreements or, more simply, because bilateral distance has a differential impact on goods of different weights; see e.g. Harrigan (2005). For this reason, we do not impose Equation (7) throughout the remainder of this paper. The role of Equation (7) here is purely to relate our results to previous theoretical work on the Ricardian model.
} 
When there are stochastic productivity differences within each industry, it is easy to check that Assumption A1 and Ranking (8) further imply:

$$
\frac{z_{i_{1}}^{1}(\omega)}{z_{i_{2}}^{1}(\omega)} \preceq \ldots \preceq \frac{z_{i_{1}}^{K}(\omega)}{z_{i_{2}}^{K}(\omega)},
$$

where $\preceq$ denotes the first-order stochastic dominance order among distributions. In other words, Ranking (9) is just a stochastic - hence weaker — version of the ordering of labor productivity $z_{i}^{k}$, which is at the heart of the Ricardian theory. Like its deterministic counterpart in (8), Ranking (9) captures the idea that country $i_{1}$ is relatively better at producing the high $k$ goods. But whatever $k$ is, country $i_{2}$ may still have lower labor requirements on some of its varieties. ${ }^{14}$

According to Corollary 2, Ranking (9) does not imply that country $i_{1}$ should only produce and export the high $k$ goods, but instead that it should produce and export relatively more of these goods. This is true irrespective of the number of countries in the economy. Unlike the standard Ricardian model, our model generates a clear and intuitive correspondence between labor productivity and exports. Here, the pattern of comparative advantage for any pair of exporters fully determines their relative export performance across industries.

The previous discussion may seem paradoxical. As we have just mentioned, Ranking (9) is a weaker version of the ordering at the heart of the standard theory. If so, how does the present theory lead to finer predictions? The answer is simple: it does not. While the standard Ricardian model is concerned with trade flows in each variety of each good, we only are concerned with the total trade flows in each good. Unlike the standard model, we recognize that random shocks - whose origins remain outside the scope of our modelmay affect the costs of production of any variety. ${ }^{15}$ Yet, by assuming that these shocks are identically distributed across a large number of varieties, we manage to generate predictions at the industry level in a multi-country world. The lack of such predictions has been the fundamental hindrance to theoretically consistent empirical work on the Ricardian model to date.

\footnotetext{
${ }^{14}$ It should be clear, however, that Ranking (9) per se does not imply the equivalence in Corollary 2. To derive this equivalence, we use Equation (5) which relies on the particular functional forms in A1.

${ }^{15}$ In this regard, our model bears a resemblance to Davis (1995) where Ricardian differences also explain intra-industry trade. However, unlike in our model, factor proportions determine inter-industry trade in Davis (1995).
} 
Having clarified how the predictions that emerge from our Ricardian model differ from those of the previous theoretical Ricardian literature, we now proceed to tighten the relationship between our model and the real world. That is, we recognize that fundamental productivity levels, which feature in Lemma 1, are not observable.

3.2. Cross-sectional Predictions. As in the previous empirical Ricardian literature, our goal is to study the relationship between observed trade flows and observed productivity levels. To do so we assume that statistical agencies perfectly observe $z_{i}^{k}(\omega)$ for all varieties of good $k$ produced in country $i$. What statistical agencies cannot observe, however, is labor productivity for varieties of good $k$ which are not produced in country $i$ because such varieties are being imported from another country. ${ }^{16}$ In other words, even in an ideal world without measurement error, statistical agencies cannot report unconditional average productivity, $E\left[z_{i}^{k}(\omega)\right]$. Instead statistical agencies can only report conditional averages, $E\left[z_{i}^{k}(\omega) \mid \Omega_{i}^{k}\right]$, based on the set of varieties actually produced in country $i, \Omega_{i}^{k} \equiv \cup_{j=1, \ldots, I} \Omega_{i j}^{k}$. From now on, we refer to $\widetilde{z}_{i}^{k} \equiv E\left[z_{i}^{k}(\omega) \mid \Omega_{i}^{k}\right]$ as observed productivity in country $i$ and industry $k$ and contrast this variable repeatedly with fundamental productivity, $z_{i}^{k}$.

Using Lemma 1 and the previous definition we now describe the impact of observed productivity differences on the cross-sectional variation of aggregate trade flows.

Theorem 3. Suppose that Assumptions A1-A4 hold. Then for any importer, $j$, any pair of exporters, $i$ and $i^{\prime}$, and any pair of goods, $k$ and $k^{\prime}$,

$$
\ln \left(\frac{\widetilde{x}_{i j}^{k} \widetilde{x}_{i^{\prime} j}^{k^{\prime}}}{\widetilde{x}_{i j}^{k^{\prime}} \widetilde{x}_{i^{\prime} j}^{k}}\right)=\theta \ln \left(\frac{\widetilde{z}_{i}^{k} \widetilde{z}_{i^{\prime}}^{k^{\prime}}}{\widetilde{z}_{i}^{k^{\prime}} \widetilde{z}_{i^{\prime}}^{k}}\right)-\theta \ln \left(\frac{d_{i j}^{k} d_{i^{\prime} j}^{k^{\prime}}}{d_{i j}^{k^{\prime}} d_{i^{\prime} j}^{k}}\right),
$$

where $\widetilde{x}_{i j}^{k} \equiv x_{i j}^{k} / \pi_{i i}^{k}$.

\footnotetext{
${ }^{16}$ This problem, which our approach will solve, was observed by Deardorff (1984) while reviewing empirical work on the Ricardian model (p. 476): "Problems arise, however, most having to do with the observability of [productivity by industry and country]. The...problem is implicit in the Ricardian model itself...[because] the model implies complete specialization in equilibrium... This in turn means that the differences in labor requirements cannot be observed, since imported goods will almost never be produced in the importing country."
} 
The proof of Theorem 3 proceeds as follows. First, we use Assumption A1 in order to establish the link between observed and fundamental productivity levels:

$$
\frac{z_{i}^{k}}{z_{i^{\prime}}^{k}}=\left(\frac{\widetilde{z}_{i}^{k}}{\widetilde{z}_{i^{\prime}}^{k}}\right) \cdot\left(\frac{\pi_{i i}^{k}}{\pi_{i^{\prime} i^{\prime}}^{k}}\right)^{1 / \theta} .
$$

The logic behind Equation (11) is fairly intuitive. In a given industry $k$, if country $i$ is more open than in country $i^{\prime}, \pi_{i i}^{k} \leq \pi_{i^{\prime} i^{\prime}}^{k}$, then country $i$ will tend to produce a smaller, but more productive subset of varieties. Hence, observed relative productivity, $\widetilde{z}_{i}^{k} / \widetilde{z}_{i^{\prime}}^{k}$, will be higher than fundamental relative productivity, $z_{i}^{k} / z_{i^{\prime}}^{k}$. The second term on the right-hand side of Equation (11) exactly corrects for this trade-driven selection. Equation (10) directly derives from Equations (5) and (11).

In our empirical analysis below we will use Theorem 3 in order to estimate directly the impact (governed by $\theta$ ) of observed productivity differences on the pattern of trade across countries and industries. Since this empirical exercise is most closely related to previous Ricardian regressions, it is important to highlight how our theory-based approach differs from previous empirical work. It does so in three respects. First, the most novel aspect of our analysis lies in the left-hand side of Equation (10). Unlike in MacDougall (1951), Stern (1962), Balassa (1963), and Golub and Hsieh (2000), the dependent variable in our cross-industry regressions will be the log of exports, disaggregated by exporting and importing countries, differenced across exporters and industries, and corrected for differences in levels of 'openness' across exporting countries. According to Theorem 3, this new measure of export performance is the theoretically correct way to control for trade-driven selection. Second, our theory clarifies how empirical work can and should control for all of the general equilibrium interactions across countries and industries that have a bearing on the partial equilibrium relationship between productivity and exports. Theorem 3 shows that these endogenous relationships do not introduce bias as long as one works with exports and productivity levels that are both in a (log-) 'difference-in-difference' form. Finally, compared to previous Ricardian tests, our microtheoretical foundations also make it possible to discuss the economic origins of the error term. In our model, these are equal to a particular form of relative trade costs. As a result, our theory makes transparent the plausibility of any orthogonality condition on which the estimation of $\theta$ in Equation (10) would be based. We will come back to this important issue in detail in Section 4. 
3.3. Counterfactual Predictions. Theorem 3 offers cross-sectional predictions which will help us test and quantify the importance of Ricardian comparative advantage in the data. An alternative way of quantifying Ricardian forces is to do counterfactual analysis, i.e. to evaluate the effects of moving to a world in which Ricardian forces do not operate across industries. In this section we pursue such an evaluation and ask: What if, for any pair of exporters, there were no fundamental relative productivity differences across industries? What would be the consequences for aggregate trade flows and welfare?

Formally, we proceed as follows. We start by fixing a reference country $i_{0}$. We assume that fundamental productivity in country $i_{0}$ is the same in all sectors in the initial and the counterfactual equilibrium: $\left(z_{i_{0}}^{k}\right)^{\prime} \equiv z_{i_{0}}^{k}$ for all $k$. By contrast, for any country $i \neq i_{0}$ and any sector $k$, we assume that fundamental productivity in sector $k$ goes from $z_{i}^{k}$ to $\left(z_{i}^{k}\right)^{\prime}$ such that $\left(z_{i}^{k}\right)^{\prime} \equiv Z_{i} \cdot z_{i_{0}}^{k}$, where $Z_{i}$ is chosen such that the value of the relative wage $\left(\mathrm{w}_{i} / \mathrm{w}_{i_{0}}\right)^{\prime}$ in the counterfactual equilibrium is the same as in the initial equilibrium $\left(\mathrm{w}_{i} / \mathrm{w}_{i_{0}}\right)$. We will come back to the exact values of $Z_{i}$ for all $i \neq i_{0}$ in a moment. In the rest of this paper, we use the convention $Z_{i_{0}} \equiv 1$ for the reference country.

It is important to note that there are no fundamental differences in relative productivity across countries in the counterfactual equilibrium. By construction, for any pair countries, $i_{1}$ and $i_{2}$, and any pair of sectors, $k_{1}$ and $k_{2}$, we have

$$
\frac{\left(z_{i_{1}}^{k_{1}}\right)^{\prime}}{\left(z_{i_{2}}^{k_{1}}\right)^{\prime}}=\frac{\left(z_{i_{1}}^{k_{2}}\right)^{\prime}}{\left(z_{i_{2}}^{k_{2}}\right)^{\prime}} .
$$

In other words, there is no source of Ricardian comparative advantage at the industry level. Furthermore, the adjustment in absolute productivity, $Z_{i}$, which is designed to hold relative wages constant around the world, guarantees that changes in fundamental productivity levels from $z_{i}^{k}$ to $\left(z_{i}^{k}\right)^{\prime}$ have no indirect terms-of-trade effects on the reference country, $i_{0}$. Accordingly, the impact of such changes on aggregate trade flows and welfare in country $i_{0}$ can be interpreted as the impact of Ricardian comparative advantage at the industry level. ${ }^{17}$ For lack of a better terminology, we will now refer to this particular comparative statics exercise as 'Removing country $i_{0}$ 's Ricardian comparative advantage.'

\footnotetext{
${ }^{17}$ Another way to see this is to note that starting from an initial equilibrium where Equation (12) holds, changes in fundamental productivity levels from $z_{i}^{k}$ to $\left(z_{i}^{k}\right)^{\prime}$ would have no impact on trade flows and welfare.
} 
The first step of our counterfactual analysis is to use the trade balance condition, Assumption A5, in order to compute the adjustment in absolute productivity, $Z_{i}$, for all $i \neq i_{0}$.

Lemma 4. Suppose that Assumptions A1-A5 hold. For all countries $i \neq i_{0}$, adjustments in absolute productivity, $Z_{i}$, can be computed as the implicit solution of

$$
\sum_{j=1}^{I} \sum_{k=1}^{K} \frac{\pi_{i j}^{k}\left(z_{i}^{k} / Z_{i}\right)^{-\theta} \alpha_{j}^{k} \gamma_{j}}{\sum_{i^{\prime}=1}^{I} \pi_{i^{\prime} j}^{k}\left(z_{i^{\prime}}^{k} / Z_{i^{\prime}}\right)^{-\theta}}=\gamma_{i}
$$

An attractive feature of Lemma 4 is that the computation of absolute productivity adjustments, $Z_{i}$, requires only a small amount of information. In particular, we do not need data on wages, factor endowments, or trade costs, which may be hard to obtain in practice. In our computation of absolute productivity adjustments (in Section 5.1), we will simply use revealed measures of fundamental productivity $z_{i}^{k}$ together with trade data which enable us to compute export shares, $\pi_{i j}^{k}$, expenditure shares, $\alpha_{j}^{k}$, and world income shares, $\gamma_{j}$.

Let $\widehat{X} \equiv X^{\prime} / X$ denote an arbitrary proportional change in any variable $X$ between the initial and the counterfactual equilibrium. Our last theoretical result can be stated as follows.

Theorem 5. Suppose that Assumptions A1-A5 hold. If we remove country $i_{0}$ 's Ricardian comparative advantage, then:

(1) Counterfactual changes in bilateral trade flows, $x_{i j}^{k}$, satisfy

$$
\widehat{x}_{i j}^{k}=\frac{\left(z_{i}^{k} / Z_{i}\right)^{-\theta}}{\sum_{i^{\prime}=1}^{I} \pi_{i^{\prime} j}^{k}\left(z_{i^{\prime}}^{k} / Z_{i^{\prime}}\right)^{-\theta}}, \text { for all } i, j, k .
$$

(2) Counterfactual changes in country $i_{0}$ 's welfare, $W_{i_{0}} \equiv w_{i_{0}} / p_{i_{0}}$, satisfy

$$
\widehat{W}_{i_{0}}=\prod_{k=1}^{K}\left[\sum_{i=1}^{I} \pi_{i i_{0}}^{k}\left(\frac{z_{i}^{k}}{z_{i_{0}}^{k} Z_{i}}\right)^{-\theta}\right]^{\alpha_{i_{0}}^{k} / \theta} .
$$

The proof of Theorem 5 is a straightforward generalization of the approach followed by Dekle, Eaton, and Kortum (2008) in the one-industry case. Again, only a very small amount of data is needed to compute counterfactual changes in bilateral trade flows and welfare, $\widehat{x}_{i j}^{k}$ and $\widehat{W}_{i_{0}}$. We still do not need any data on wages, factor endowments, or trade costs. All the economically relevant information about these variables is already included in the $\pi_{i j}^{k}$ s.

Equations (14) and (15) are both intuitive. Since our adjustment of absolute productivity levels, $Z_{i}$, controls for any indirect terms-of-trade effect, changes in bilateral trade flows, 
$\widehat{x}_{i j}^{k}$, should mechanically reflect changes in the productivity of exporter $i$ relative to other exporters $i^{\prime},\left(z_{i}^{k} / Z_{i}\right) /\left(z_{i^{\prime}}^{k} / Z_{i^{\prime}}\right)$, weighted by the importance of these exporters in each importing country and industry, $\pi_{i^{\prime} j}^{k}$. Similarly, Equation (15) states that changes in welfare, $\widehat{W}_{i_{0}}$, should mechanically reflect the changes in relative prices due to the changes in productivity of different exporters with the $\pi_{i j}^{k}$ s providing the economically relevant weights, namely the share of expenditures on goods from country $i$ in country $j$ and industry $k$.

3.4. Robustness. The previous theoretical predictions have been derived under strong functional form restrictions. In particular, we have assumed, as in Eaton and Kortum (2002), that labor productivity was drawn from an extreme value distribution, Assumption A1. Before turning to our empirical analysis, we now briefly discuss the robustness of our results.

The crucial assumption behind Lemma 1 is that the elasticity of bilateral trade flows, $x_{i j}^{k}$, with respect to trade and production costs, $c_{i j}^{k}$, is constant. In Lemma 1 , this elasticity is given by our measure of intra-industry heterogeneity, $\theta$, which creates a tight relationship between the variations in relative productivity and relative exports. While Assumption A1 is sufficient for the elasticity of trade flows to be constant, it is not necessary. In Appendix $\mathrm{B}$, we show that the elasticity of trade flows would remain constant for any distribution of productivity shocks, provided that: $(i)$ differences in the distribution of productivity across countries and industries, $F_{i}^{k}$, can still be parameterized by a single location parameter, $z_{i}^{k}$; (ii) differences in trade and production costs are small, $c_{1 j}^{k} \simeq \ldots \simeq c_{I j}^{k}$; and (iii), elasticities of substitution are constant across countries and industries, $\sigma_{j}^{k}=\sigma$. The intuition is simple. On the one hand, conditions $(i)$ and $(i i)$ guarantee that marginal changes in trade and production costs $c_{i j}^{k}$ have the same impact on the extensive margin across countries and industries, i.e., on how many varieties are being exported. On the other hand, condition (iii) guarantees that they have the same impact on the intensive margin, i.e. on how much of each variety is being exported. Thus, the elasticity of trade flows must be constant. Lemma 1 and Corollary 2 directly follow. ${ }^{18}$

\footnotetext{
${ }^{18}$ Since Lemma 1 relies on the elasticity of trade flows being constant, it may be surprising that no restriction was imposed on the variations of the elasticity of substitution, $\sigma_{j}^{k}$, in Assumption A4. Condition ( iii) was not necessary in Lemma 1 because of one key property of the Fréchet distribution: like in Eaton and Kortum (2002), the distribution of the price $p_{j}^{k}(\omega)$ of a given variety $\omega$ of good $k$ in country $j$ is independent of the country of origin $i$; see Eaton and Kortum (2002) p1748 for a detailed discussion. Formally, if $F_{i}^{k}(\cdot)$ satisfies Equation (1), then $\operatorname{Pr}\left\{p_{j}^{k}(\omega) \leq p\right\}=\operatorname{Pr}\left\{p_{j}^{k}(\omega) \leq p \mid c_{i j}^{k}(\omega)=\min _{1 \leq i^{\prime} \leq I} c_{i^{\prime} j}^{k}(\omega)\right\}$, for any $p>0$ and
} 
In Appendix B, we also discuss the importance of adjusting bilateral exports for differences in levels of openness, $\pi_{i i}^{k}$, in order to correct for the endogenous difference between fundamental and observed productivity levels. Without Assumption A1, one cannot obtain closed-form solutions for the extent of trade-driven selection, and so, one cannot derive Theorem 3. However, we show that even without Assumption A1, the $\pi_{i i}^{k} \mathrm{~s}$ still contain useful information about the difference between fundamental and observed productivity levels. In particular, they should still be controlled for when estimating the impact of productivity differences on bilateral trade flows under conditions $(i)$ - $(i i i)$. Put simply, the particular way in which we control for differences in levels of openness, $\pi_{i i}^{k}$, is functional form dependent, but the general idea that the relationship between fundamental and observed productivity depends on these levels is not.

Finally, we show that Theorem 5 would also hold under conditions $(i)-(i i i)$ if fundamental productivity differences across countries are initially small, $z_{i}^{k} \simeq \ldots \simeq z_{I}^{k}$; see Appendix $\mathrm{B}$ for details. ${ }^{19}$ To summarize, in a world economy featuring small technological differences across countries, our main cross-sectional and counterfactual predictions would hold under weaker restrictions on the distribution of intra-industry productivity shocks. The main role of Assumption A1 is to help us go from local to global predictions, which hold for arbitrarily large differences across countries and industries.

\section{Cross-sectional Results}

In this section, we investigate how much observed productivity differences affect the crosssectional variation of bilateral trade flows. That is, we test Theorem 3 using the best available data on internationally comparable productivity and trade flows across countries and industries. This procedure will highlight how empirical tests of the Ricardian model should be performed in a theory-consistent manner. It will also allow us to estimate the parameter $\theta$, which is the only structural parameter needed to ask questions about counterfactuals within this Ricardian model (the goal of Section 5).

any $1 \leq i \leq I$. Unfortunately, this property does not generalize to any other standard distribution, as we have shown formally in an earlier version of this paper, Costinot and Komunjer (2007).

${ }^{19}$ For the second of our counterfactual results, Equation (15), condition (ii) can actually be dispensed with altogether. 


\section{Table 1: Data Set Description}

\begin{tabular}{|c|c|c|}
\hline Sources: & \multicolumn{2}{|l|}{$\begin{array}{l}\text { OECD STAN Bilateral Trade Database (Edition 2008); International Comparisons of } \\
\text { Output and Productivity Industrial Database (Timmer, Ypma and van Ark, 2007). }\end{array}$} \\
\hline Year: & \multicolumn{2}{|l|}{1997} \\
\hline Countries: & \multicolumn{2}{|l|}{$\begin{array}{l}\text { Australia, Belgium-Luxembourg (aggregated into one country unit to enable a merge with } \\
\text { the productivity data), Czech Republic, Denmark, Spain, Finland, France, Germany, } \\
\text { Greece, Hungary, Ireland, Italy, Japan, Korea, Netherlands, Poland, Portugal, Slovakia, } \\
\text { Sweden, United Kingdom, and United States }\end{array}$} \\
\hline Industry: & STAN Description: & 1 Code \\
\hline Food & Food products, beverages and tobacco & $15-16$ \\
\hline Textiles & Textiles, textile products, leather and footwear & $17-19$ \\
\hline Wood & Wood and products of wood and cork & 20 \\
\hline Paper & Pulp, paper, paper products, printing and publishing & $21-22$ \\
\hline Fuel & Coke, refined petroleum products, and nuclear fuel & 23 \\
\hline Chemicals & Chemicals, and chemical products & 24 \\
\hline Plastic & Rubber and plastics products & 25 \\
\hline Minerals & Other non-metallic mineral products & 26 \\
\hline Metals & Basic metals, and fabricated metal products, except machinery and equipment & $27-28$ \\
\hline Machinery & Machinery and equipment not elsewhere classified & 29 \\
\hline Electrical & Electrical and optical equipment & $30-33$ \\
\hline Transport & Transport equipment & $34-35$ \\
\hline Misc. Manuf. & Manufacturing not elsewhere classified & $36-37$ \\
\hline
\end{tabular}

4.1. Data. Our baseline tests require data of just two types: trade flows and productivity. In this section we outline the sources of these data.

4.1.1. Trade Flows. We use trade flow data taken from the OECD Structural Analysis (STAN) Bilateral Trade Database (edition 2008) relating to the year of 1997. Our selection of countries and industries (and the year, 1997) is driven entirely by the availability of both bilateral trade flow data and high quality productivity data. The resulting sample comprises 21 countries (18 European countries plus Japan, Korea and the United States) and 13 industries which correspond to roughly two-digit ISIC codes and span the manufacturing sector, as described in Table 1. 
We use the value of bilateral exports from each of these 21 countries $(i)$ to each of these 21 countries $(j)$ in each industry $(k)$ as our measure of $x_{i j}^{k}{ }^{20}$ The final source of trade data that we require concerns how much each exporting country $i$ imports in each industry $k$ relative to its total expenditure in that industry, in order to correct for the endogenous selection of varieties that are actually produced domestically, i.e. $\pi_{i i}^{k}$ in Theorem 3 above. For this purpose we use data on the import penetration ratio, which is equal to $1-\pi_{i i}^{k}$, of each exporting country $i$ and industry $k$, as reported in the OECD STAN database.

4.1.2. Productivity. Measuring productivity at the country-industry level is a non-trivial exercise. ${ }^{21}$ As Bernard, Eaton, Jensen, and Kortum (2003) point out (p. 1274), "under perfect competition, prices vary inversely with efficiency exactly to eliminate any variation in productivity, measured as the value of output per unit input." Accordingly, real output per worker - a typical proxy for labor productivity in the existing literature that is constructed as nominal output per worker divided by a producer price index - is only an informative measure of productivity to the extent that it uses the correct price deflator. In a Ricardian world, variations in relative productivity levels should be fully reflected in relative producer prices. $^{22}$

With this in mind, and in line with the Ricardian assumptions made in Section 2, we measure the variation in productivity across countries and industries using differences in producer price indices. Our producer price data are taken from the GGDC Productivity Level Database; see Timmer, Ypma, and van Ark (2007) for details. In this database, raw

\footnotetext{
${ }^{20}$ Our sample of exporting countries and industries is fundamentally constrained by the intersection of available trade flow and productivity data. However, for many of the exporter-industry pairs in our sample data on exports are available for many import destinations, not just for imports to another of the 21 countries in our sample. The cross-sectional estimates of $\theta$ presented below change only trivially if trade flow data to all available import destinations are included in the sample. Our procedure for computing counterfactuals discussed below, however, requires the full ('square') matrix of imports and exports, so this procedure can only be performed on the 21 countries in our main sample. It is for this reason that we prefer to use the full 'square' sample throughout.

${ }^{21}$ See, for example, Harrigan (1997a) for a review of the difficulties involved in comparing productivity levels across countries and industries.

${ }^{22}$ More specifically, in the context of our model, for any pair of goods, $k$ and $k^{\prime}$, and any pair of countries, $i$ and $i^{\prime}$, Assumptions A2 and A3 imply $\frac{\widetilde{z}_{i}^{k} \widetilde{z}_{i^{\prime}}^{k^{\prime}}}{\widetilde{z}_{i^{\prime}}^{k} \widetilde{z}_{i}^{k^{\prime}}}=\frac{E\left[p_{i}^{k}(\omega) \mid \Omega_{i}^{k}\right] E\left[p_{i^{\prime}}^{k^{\prime}}(\omega) \mid \Omega_{i^{\prime}}^{k^{\prime}}\right]}{E\left[p_{i^{\prime}}^{k}(\omega) \mid \Omega_{i^{\prime}}^{k}\right] E\left[p_{i}^{k^{\prime}}(\omega) \mid \Omega_{i}^{k^{\prime}}\right]}$.
} 
price data observations are first collected at the plant level for several thousands of products (often with hundreds of products per industry, which we interpret as varieties in the context of our model). This is only made possible due to the use of the PRODCOM system of homogeneous product descriptions within the EU and OECD. The GGDC database uses the PRODCOM system to pay particular attention to matching products in different countries in order to control for quality differences. These prices are then aggregated up into a unique producer price index at the industry level using output data. We take the inverse of this producer price index as the empirical counterpart of $\widetilde{z}_{i}^{k}$ in our model. ${ }^{23}$ Our measures of productivity across countries and industries are reported in Table 2.

A few comments about this procedure are in order. First, the productivity levels reported in Table 2 are normalized to one in all industries for the United States and in all countries for the Food industry. It should be clear that this is without any loss of generality and has no impact on our analysis. At its core, the notion of Ricardian comparative advantage involves the comparison of two goods and two countries, which is reflected in the fact that predicted export behavior (in Theorem 3) depends only on the difference-in-difference in $\ln \widetilde{z}_{i}^{k}$.

Second, the main benefit of our approach is that our independent variable is consistent with the model developed in Section 2. In particular, we explicitly recognize that: $(i)$ all information about relative productivity levels in the data is fully reflected in relative producer prices; and (ii), average productivity levels can only be measured using varieties that have actually been produced. The main drawback of our approach, of course, is that the crosssectional variation in producer prices is likely to reflect more than productivity differences in practice. In particular, variation in producer prices may also capture differences in factor

\footnotetext{
${ }^{23}$ It is worth pointing out that producer price indices from the GGDC database relate to gross output. We believe that such measures are well suited for our empirical exercise for two reasons. First, as we discuss in more detail below, our theory is fundamentally one of comparative costs. When perfectly competitive producers (like those in our model) use intermediate inputs in production, it is the prices of their gross output that are equal to their unit costs. Second, the GGDC database is primarily concerned with collecting internationally comparable producer output rather than input prices, so we expect producer prices of gross output to be the best measured proxy for productivity available. Nevertheless, for robustness, Section 4.3 below considers an extension that aims to control for the variation in input prices (and input intensity) across countries and industries.
} 
Table 2: Relative Productivity Levels, by Country and Industry

\begin{tabular}{lcccccccccccccc}
\hline & Food & $\begin{array}{c}\text { Tex- } \\
\text { tiles }\end{array}$ & Wood & Paper & Fuel & $\begin{array}{c}\text { Chem- } \\
\text { icals }\end{array}$ & Plastic & $\begin{array}{c}\text { Min- } \\
\text { erals }\end{array}$ & Metals & $\begin{array}{c}\text { Mach- } \\
\text { inery }\end{array}$ & $\begin{array}{c}\text { Elec- } \\
\text { trical }\end{array}$ & $\begin{array}{c}\text { Trans- Misc. } \\
\text { port }\end{array}$ & Manuf \\
\hline AUS & 1 & 0.77 & 0.89 & 0.85 & 1.21 & 0.84 & 0.81 & 1.00 & 0.84 & 0.86 & 0.82 & 0.74 & 0.84 \\
BEL & 1 & 0.84 & 0.84 & 1.03 & 1.70 & 1.26 & 1.71 & 1.49 & 1.07 & 0.93 & 0.86 & 0.71 & 1.11 \\
CZE & 1 & 0.80 & 1.16 & 0.72 & 0.66 & 1.44 & 1.65 & 1.88 & 1.05 & 0.97 & 0.93 & 0.78 & 0.85 \\
DEN & 1 & 0.75 & 0.84 & 0.63 & 0.64 & 1.02 & 1.01 & 0.98 & 0.85 & 0.85 & 0.63 & 0.51 & 1.35 \\
ESP & 1 & 0.92 & 1.47 & 0.91 & 0.70 & 1.34 & 1.38 & 1.58 & 1.08 & 0.99 & 1.08 & 1.01 & 1.15 \\
FIN & 1 & 0.82 & 1.20 & 1.18 & 0.86 & 1.69 & 1.37 & 1.30 & 1.18 & 1.13 & 0.90 & 0.65 & 1.47 \\
FRA & 1 & 0.76 & 1.22 & 0.93 & 1.11 & 1.24 & 1.64 & 1.28 & 1.08 & 1.13 & 0.93 & 0.84 & 0.92 \\
GER & 1 & 0.67 & 0.91 & 0.89 & 0.94 & 1.03 & 1.23 & 1.20 & 0.91 & 0.92 & 0.80 & 0.72 & 0.90 \\
GRE & 1 & 1.07 & 1.65 & 1.57 & 1.13 & 1.87 & 1.21 & 2.19 & 1.51 & 1.54 & 1.26 & 0.83 & 1.36 \\
HUN & 1 & 0.80 & 1.05 & 1.08 & 0.52 & 0.98 & 1.32 & 1.33 & 0.91 & 1.52 & 0.83 & 0.49 & 1.14 \\
IRE & 1 & 0.93 & 1.03 & 0.81 & 1.15 & 1.49 & 1.55 & 1.19 & 1.11 & 0.92 & 0.74 & 0.62 & 1.11 \\
ITA & 1 & 0.79 & 1.02 & 0.68 & 0.65 & 1.26 & 1.48 & 1.63 & 1.17 & 1.02 & 0.98 & 1.14 & 0.94 \\
JPN & 1 & 1.88 & 1.37 & 1.69 & 1.06 & 1.84 & 1.69 & 1.71 & 1.85 & 2.05 & 1.96 & 1.96 & 1.33 \\
KOR & 1 & 1.23 & 1.56 & 1.40 & 1.32 & 2.74 & 1.97 & 2.22 & 1.50 & 1.64 & 1.60 & 1.72 & 1.94 \\
NED & 1 & 0.85 & 0.54 & 0.76 & 0.65 & 1.25 & 1.26 & 1.11 & 1.00 & 0.71 & 0.75 & 0.61 & 0.74 \\
POL & 1 & 1.15 & 1.12 & 0.92 & 1.07 & 1.24 & 2.21 & 1.59 & 0.91 & 0.80 & 0.60 & 0.68 & 0.64 \\
PTL & 1 & 1.18 & 1.32 & 1.08 & 0.62 & 1.26 & 2.32 & 1.66 & 1.42 & 1.01 & 1.01 & 0.59 & 0.91 \\
SLK & 1 & 0.63 & 0.82 & 0.91 & 0.49 & 1.04 & 1.07 & 1.45 & 0.71 & 0.63 & 0.72 & 0.65 & 0.89 \\
SWE & 1 & 0.68 & 1.18 & 0.92 & 0.78 & 1.22 & 1.18 & 0.92 & 1.14 & 0.98 & 0.89 & 0.67 & 1.09 \\
UK & 1 & 0.92 & 0.69 & 1.23 & 1.27 & 1.20 & 1.74 & 1.24 & 1.02 & 1.29 & 0.97 & 0.79 & 1.80 \\
USA & 1 & 1 & 1 & 1 & 1 & 1 & 1 & 1 & 1 & 1 & 1 & 1 & 1 \\
\hline
\end{tabular}

Notes: Country and industry productivity, as measured by the inverse of producer prices (as collected by the GGDC Productivity Level Database). Entries are normalized to reflect relative productivity levels in the manner suggested by equation (10). That is, within each industry the USA has productivity equal to 1 , and within each country the 'Food' industry (ISIC Rev 3.1 code: 15-16) has productivity equal to 1 . Countries are listed in the order presented in Table 1.

prices and factor intensity across countries and industries, as emphasized in the HeckscherOhlin model. ${ }^{24}$ While such considerations would not affect our main specification (which uses producer price differences to measure unit cost differences accurately regardless of the source of these differences), they are obviously crucial for how one should interpret our results. We will come back to this important issue in Section 4.3 below.

Finally, another concern with our approach is related to the way the GGDC Productivity Level Database has been constructed in practice. Because of data limitations, producer prices are sometimes combined with expenditure prices to generate producer price indices at the

\footnotetext{
${ }^{24}$ The exact same issue would arise if we were to use real output per worker as our measure of productivity.
} 
industry-level in the GGDC Productivity Level Database. This is, of course, problematic for the purposes of our Ricardian approach since expenditure prices may be uncorrelated with domestic productivity, which is what we are ultimately interested in. ${ }^{25}$ We explore the consequences for our estimates of this data limitation in Section 4.4 below.

4.2. Baseline Results. Following Theorem 3, we estimate the following log-linear model using the data described above

$$
\ln \left(\frac{\widetilde{x}_{i j}^{k} \widetilde{x}_{i^{\prime} j}^{k^{\prime}}}{\widetilde{x}_{i j}^{k^{\prime}} \widetilde{x}_{i^{\prime} j}^{k}}\right)=\theta \ln \left(\frac{\widetilde{z}_{i}^{k} \widetilde{z}_{i^{\prime}}^{k^{\prime}}}{\widetilde{z}_{i}^{k^{\prime}} \widetilde{z}_{i}^{k}}\right)+\ln \left(\frac{\varepsilon_{i j}^{k} \varepsilon_{i^{\prime} j^{\prime}}^{k^{\prime}}}{\varepsilon_{i j}^{k^{\prime}} \varepsilon_{i^{\prime} j^{\prime}}^{k}}\right),
$$

where $\ln \widetilde{x}_{i j}^{k} \equiv \ln x_{i j}^{k}-\ln \pi_{i i}^{k}$ is (log) 'corrected exports' from country $i$ to country $j$ in industry $k$, or (log) exports adjusted for openness in country $i$ and industry $k, \ln \pi_{i i}^{k}$; and $\ln \widetilde{z}_{i}^{k}$ is $(\log )$ observed productivity. The error term $\varepsilon_{i j}^{k}$ captures both the variation in (log) variable trade $\operatorname{costs},-\theta \ln d_{i j}^{k}$, as well as any measurement error in bilateral trade flows.

As mentioned earlier, the (log) difference-in-difference in Equation (10) and its empirical counterpart, Equation (16) above, highlight the essence of trade based on Ricardian comparative advantage. That is, relative productivity differences across any pair of countries and industries drive relative export levels to any market $j$. While it is possible to estimate Equation (16) in this form, it is simpler - and closer to existing empirical work - if we estimate the following equivalent specification:

$$
\ln \widetilde{x}_{i j}^{k}=\delta_{i j}+\delta_{j}^{k}+\theta \ln \widetilde{z}_{i}^{k}+\varepsilon_{i j}^{k}
$$

In this expression $\delta_{i j}$ represents an importer-exporter fixed effect and $\delta_{j}^{k}$ an importer-industry fixed effect. ${ }^{26}$ Under the assumption that variable trade costs (and other components of the error term, $\varepsilon_{i j}^{k}$ ) are orthogonal to observed productivity, an OLS estimate of Equation (17) provides an unbiased estimate of $\theta$, the extent of intra-industry heterogeneity in this model. We come back to the plausibility of this orthogonality restriction in a moment.

\footnotetext{
${ }^{25}$ Again, the exact same issue would arise if we were to use alternative measures of productivity because all such internationally comparable measures use indices of (supposedly) producer prices in their construction.

${ }^{26}$ Since we have a full set of importer-exporter fixed effects, $\delta_{i j}$, note that this estimation strategy subsumes exporter fixed effects and importer fixed effects.
} 


\section{Table 3: Cross-Sectional Results - Baseline}

\begin{tabular}{|c|c|c|c|c|}
\hline Dependent variable: & $\begin{array}{l}\log \text { (corrected } \\
\text { exports) }\end{array}$ & $\log$ (exports) & $\begin{array}{l}\log \text { (corrected } \\
\text { exports) }\end{array}$ & $\log$ (exports) \\
\hline & (1) & (2) & (3) & (4) \\
\hline log (productivity based on producer prices) & $\begin{array}{l}1.123^{\star \star *} \\
(0.0994)\end{array}$ & $\begin{array}{l}1.361^{\star * *} \\
(0.103)\end{array}$ & $\begin{array}{c}6.534^{\star * *} \\
(0.708)\end{array}$ & $\begin{array}{l}11.10^{\star * *} \\
(0.981)\end{array}$ \\
\hline Estimation method & OLS & OLS & IV & IV \\
\hline Exporter $\mathrm{x}$ Importer fixed effects & YES & YES & YES & YES \\
\hline Industry x Importer fixed effects & YES & YES & YES & YES \\
\hline Observations & 5,652 & 5,652 & 5,576 & 5,576 \\
\hline R-squared & 0.856 & 0.844 & 0.747 & 0.460 \\
\hline
\end{tabular}

Notes: Regressions estimating equation (17) using data from 21 countries and 13 manufacturing sectors (listed in Table 1) in 1997. 'Exports' is the value of bilateral exports from the exporting country to the importing country in a given industry. 'Corrected exports' is 'exports' divided by the share of the exporting country's total expenditure in the given industry that is sourced domestically (equal to one minus the country and industry's import penetration ratio). 'Productivity based on producer prices' is the inverse of the average producer price in an exporter-industry. Columns 3 and 4 use the log of 1997 R\&D expenditure as an instrument for productivity. Data sources and construction are described in full in Section 4.1. Heteroskedasticity-robust standard errors are reported in parentheses. ${ }^{* *}$ indicates statistically significantly different from zero at the $1 \%$ level.

The first column of Table 3 reports a preliminary estimate of $\theta$, from estimating Equation (17) by OLS. In line with the prediction in Theorem 3, this estimate is positive and statistically significant. ${ }^{27}$ According to this estimate of the productivity-to-exports elasticity, a $1 \%$ change in productivity is, all else held equal, associated with a 1.1\% change in exports.

Column 2 of Table 3 reports the OLS estimate of $\theta$ if the dependent variable is not adjusted for the difference between fundamental and observed productivity highlighted by Theorem 3. Without this adjustment we see that one would tend to overestimate the importance of productivity differences. This is intuitive. Observed productivity differences are smaller

${ }^{27}$ The standard errors reported in Tables 3 and 4 are adjusted for unrestricted forms of heteroskedasticity. Standard errors that are clustered at the exporter-industry level are larger, as one would expect if the error term $\varepsilon_{i j}^{k}$ in Equation (17) is correlated across exporter destinations. But our preferred estimate of $\theta$ is still statistically significant at standard levels when based on standard errors that are clustered at the exporter-industry level. 
than fundamental productivity differences since countries with low fundamental productivity levels only produce varieties for which they get very good productivity draws. Thus without our correction, one would wrongly infer that smaller productivity differences lead to the same variation in trade flows, thereby overestimating the elasticity $\theta$ of trade flows with respect to productivity.

There are two main reasons to be concerned with the previous OLS estimates of Equation (17) introduced above: $(i)$ simultaneity bias, due to agglomeration effects through which higher export levels lead to higher productivity levels; and ( $i i)$ attenuation bias, due to measurement error in productivity. To attempt to circumvent these two potential sources of bias, we estimate Equation (17) by the method of instrumental variables, with the endogenous regressor - productivity levels $\left(\ln \widetilde{z}_{i}^{k}\right.$ ) -instrumented with (the log of) research and development (R\&D) expenditures at the country-industry level. ${ }^{28}$ This approach follows Eaton and Kortum (2002) and Griffith, Redding, and Van Reenen (2004) in modeling technology as a function of R\&D activity. In doing so, our identifying assumption is that relative R\&D expenditures are correlated with relative bilateral trade flows only through their impact on relative productivity, i.e. relative producer prices.

Our IV estimate of $\theta$ is reported in column 3 of Table $3 .{ }^{29}$ This is our preferred specification. Compared to the OLS estimates, the magnitude of $\theta$ is considerably larger - 6.53 rather than 1.12 - and still statistically significant. This increase is consistent with the likely scenario in which our OLS estimates suffer from attenuation bias because producer prices are extremely difficult to measure accurately in practice. ${ }^{30}$ Finally, in column 4 of Table 3 we see that if we were not adjusting for the distinction between fundamental and observed

\footnotetext{
${ }^{28}$ Data on R\&D expenditure are from the Analytical Business Enterprise Research and Development (ANBERD) database collected by the OECD — as used, for example, by Griffith, Redding, and Van Reenen (2004). Wherever possible this source aims to break down the R\&D expenditures of large, multi-industry firms, as well as those of enterprise-serving research institutes, into expenditures by output product.

${ }^{29}$ The instrument has strong predictive power. When run only across exporters and industries (that is, utilizing only the meaningful variation in the first stage), the heteroskedasticity-robust t-statistic in the first-stage is equal to 2.23 .

${ }^{30}$ Agglomeration effects have a priori ambiguous effects on our estimates of $\theta$. To see this, suppose, using the more compact notation of Equation (16), that observed productivity, $\widetilde{z}_{i}^{k}$, and adjusted trade flows, $\widetilde{x}_{i j}^{k}$,
} 
productivity, the value of our estimate of $\theta$ would be significantly biased upwards (from 6.53 to over 11) in both statistical and economic senses. ${ }^{31}$

Taken together, our findings in Table 3 highlight the importance of the endogeneity of relative productivity (and hence the importance of IV estimation relative to OLS estimation), and the importance of correcting for the trade-driven wedge between observed and fundamental productivity levels, as emphasized in Theorem 3.

In Sections 4.3 and 4.4 below we document that our core finding (in column 3 of Table 3 ) is robust to a variety of specification checks. Before moving on to these robustness checks, however, it is important to note that our preferred estimate of $\theta=6.53$ is in line with previous estimates of $\theta$ obtained by researchers using different methodologies. In particular, Eaton and Kortum (2002) estimate $\theta$ to be 3.60 using wage data, and either 8.28 or 12.86 using data on price gaps between countries (to proxy for trade costs); Simonovska and Waugh (2009) amend Eaton and Kortum's (2002) price gap methodology (using both Eaton and Kortum's (2002) price data and an improved round of the underlying ICP price data) and estimate $\theta$ to be 4.5 regardless of the sample. Finally, Donaldson (2008) estimates $\theta$ commodity-by-commodity in colonial India using a trade costs approach and finds an average (over 85 commodities) of 5.2 , with a standard deviation of 2.1 .

4.3. Alternative Productivity Measures. In the previous subsection, we have taken the Ricardian model developed in Section 2 very seriously, interpreting differences in producer prices as differences in productivity. As previously mentioned, there are good reasons to

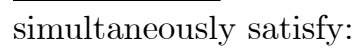

$$
\begin{aligned}
& \ln \left(\begin{array}{l}
\widetilde{x}_{i j}^{k} \widetilde{x}_{i^{\prime} j^{\prime}}^{k^{\prime}} \\
\widetilde{x}_{i j}^{k^{\prime}} \widetilde{x}_{i^{\prime} j^{\prime}}^{k}
\end{array}\right)=\theta \ln \left(\frac{\widetilde{z}_{i}^{k} \widetilde{z}_{i^{\prime}}^{k^{\prime}}}{\widetilde{z}_{i}^{k^{\prime}} \widetilde{z}_{i}^{k}}\right)+\ln \left(\frac{\varepsilon_{i j}^{k} \varepsilon_{i^{\prime} j^{\prime}}^{k^{\prime}}}{\varepsilon_{i j}^{k^{\prime}} \varepsilon_{i^{\prime} j^{\prime}}^{k}}\right), \\
& \ln \left(\frac{\widetilde{z}_{i}^{k} \widetilde{z}_{i^{\prime}}^{k^{\prime}}}{\widetilde{z}_{i}^{k^{\prime}} \widetilde{z}_{i}^{k}}\right)=\alpha \ln \left(\frac{\widetilde{x}_{i j}^{k} \widetilde{x}_{i^{\prime} j^{\prime}}^{k^{\prime}}}{\widetilde{x}_{i j}^{k^{\prime}} \widetilde{x}_{i^{\prime} j^{\prime}}^{k}}\right)+\ln \left(\frac{\eta_{i j}^{k} \eta_{i^{\prime} j^{\prime}}^{k^{\prime}}}{\eta_{i j}^{k^{\prime}} \eta_{i^{\prime} j^{\prime}}^{k}}\right),
\end{aligned}
$$

where $\alpha>0$ captures the fact that higher levels of exports lead to higher productivity levels. If $\eta_{i j}^{k}$ is orthogonal to $\varepsilon_{i^{\prime} j^{\prime}}^{k^{\prime}}$ for all $i, i^{\prime}, j, j^{\prime}, k$, and $k^{\prime}$, then $E\left[\ln \left(\frac{\widetilde{z}_{i}^{k} \widetilde{z}_{i^{\prime}}^{k^{\prime}}}{\widetilde{z}_{i}^{k^{\prime}} \widetilde{z}_{i}^{k}}\right) \cdot \ln \left(\frac{\varepsilon_{i j}^{k} \varepsilon_{i^{\prime} j^{\prime}}^{k^{\prime}}}{\varepsilon_{i j}^{k^{\prime}} \varepsilon_{i^{\prime} j^{\prime}}^{k}}\right)\right]>0$ if and only if $\alpha \theta<1$.

${ }^{31}$ By statistical sense, we formally mean the following. If we estimate a full, three-equation system (in which equation 1 is the first-stage relationship between observed productivity and R\&D expenditure, equation 2 is the second-stage relationship estimated in column 3 of Table 3 , and equation 3 is the secondstage relationship estimated in column 4 of Table 3) that allows for correlation among the error terms across equations, the chi-squared test for equality of the coefficient estimate of $\theta$ in equation 2 and the estimate of $\theta$ in equation 3 has a p-value that is smaller than 0.001 . 
believe that the variation in producer prices may reflect more than productivity differences in practice. The objective of this subsection is to discuss how the introduction of additional factors of production would affect our empirical analysis and the interpretation of our empirical results.

The first thing to notice is that our main specification, Equation (17), does not rely on the assumption that there only is one factor of production (or that there are no intermediate inputs to production). Our theory is fundamentally one of comparative costs. These costs relate one-for-one with producer prices in a perfectly-competitive setting, regardless of whether the determinants of production costs are productivity or factor price differences. With multiple factors of production (or intermediate inputs), the relationship between bilateral imports and producer prices would still be given by Equation (17), with $\theta$ now representing intraindustry heterogeneity in terms of Total Factor Productivity (TFP). ${ }^{32}$ Thus, the only issue related to the previous empirical results is one of interpretation, to which we now turn.

Econometrically, our IV estimates reflect the impact of predicted changes in producer prices conditional on $R \& D$ expenditures. If $R \& D$ expenditures affect producer prices only through changes in TFP, our IV estimates should therefore capture, in line with our Ricardian interpretation, the impact of TFP differences on bilateral trade flows. In order to assess the validity of this interpretation formally, we estimate $\theta$ using a measure of TFP rather than producer price data. Since the GGDC Productivity Level Database also reports data on the prices and shares of labor, capital, and material inputs, (log-) TFP measures can be computed in the standard 'dual' fashion: as the (log-) difference between the producer price and the sum of (log-) factor prices weighted by their factor shares, as in Jorgensen and Griliches (1967). ${ }^{33}$

Having constructed this dual TFP measure of productivity in order to control for factor price and intensity differences, we then regress exports on productivity, as in Equation (17), using this TFP measure of productivity rather than producer prices as before. The new IV estimate of $\theta$ in this regression is reported in column 2 of Table 4 . While the estimate of $\theta$ increases slightly to 6.70 (when compared with our previous estimate of 6.53 , reported

\footnotetext{
${ }^{32}$ The proof is trivial and omitted; see e.g. Appendix E in Costinot and Komunjer (2007).

${ }^{33}$ That is, our 'dual' (log-) TFP measure is calculated as $\ln T F P_{i}^{k}=\ln p_{i}^{k}-\alpha_{i, L}^{k} \ln w_{i}^{k}-\alpha_{i, K}^{k} \ln r_{i}^{k}-$ $\alpha_{i, M}^{k} \ln m_{i}^{k}$, where the variables $\alpha$ refer to factor shares of labor, capital and material inputs, respectively, and $w_{i}^{k}, r_{i}^{k}$ and $m_{i}^{k}$ refer to the wage rate, capital rental rate, and material inputs price, respectively.
} 


\section{Table 4: Cross-Sectional Results - Alternative Productivity Measures}

Dependent variable in all regressions: corrected exports

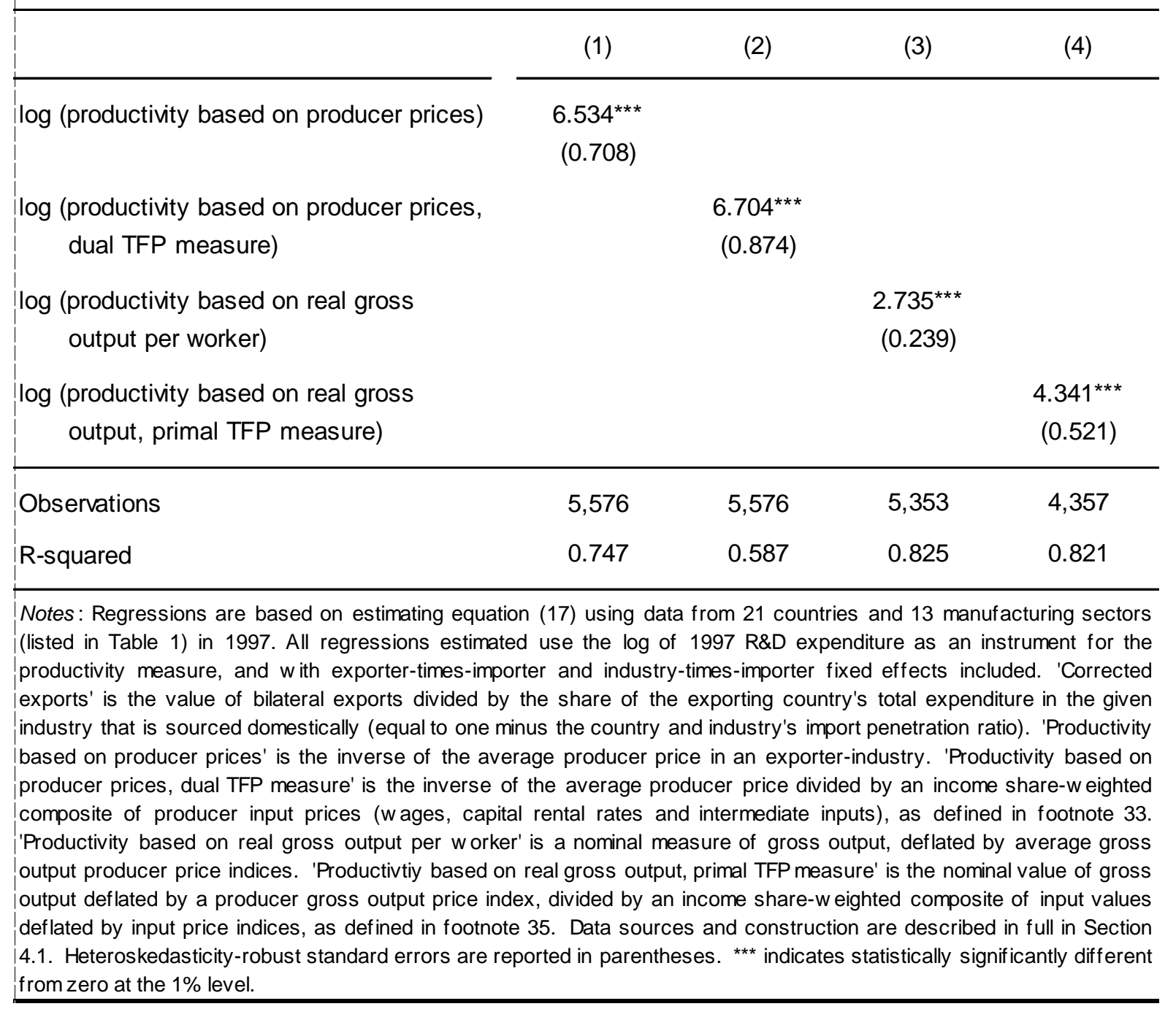

again in column 1 of Table 4 for convenience) it is still positive and significantly different from zero, in line with Theorem 3. Further, this new estimate lies comfortably within the 95 percent confidence interval of our previous estimate (and also within the bounds of estimates of $\theta$ previously obtained in the literature, as discussed above). Both of these findings lend strong support to our Ricardian interpretation of the results presented in Table 3. Although our use of relative producer prices to measure relative productivity is a priori consistent with any theory of comparative costs - regardless of the number of non-tradable factors of 
production - the estimates in columns 1 and 2 of Table 4 imply that Ricardian motives for cross-industry trade (at least those contained in the component of productivity that is correlated with R\&D expenditure) appear to be orthogonal to Heckscher-Ohlin motives in our data. ${ }^{34}$

The remaining two columns of Table 4 report estimates from regressions in which two alternative proxies for productivity are used. These alternatives are all variations of 'primal' measures of labor and multi-factor productivity: real gross output per worker and TFP calculated in the primal manner rather than the dual manner introduced above. ${ }^{35}$ Each column contains the resulting estimate of $\theta$ from a separate regression, each of which is an IV regression of Equation (17) using one of the above alternative productivity proxies as a measure of $\widetilde{z}_{i}^{k}$.

Estimates of $\theta$ based on these alternative productivity measures are both somewhat lower than our preferred estimate (in column 1). This is consistent with the idea that these alternative productivity proxies are mismeasured (and that this measurement error problem is not entirely obviated by our instrumental variable procedure). As we have argued above, in a Ricardian environment relative producer prices contain all of the relevant information about relative productivity levels. Because our two alternative productivity measures are constructed using data on producer prices plus additional variables (such as nominal output and the number of workers in the case of real output per worker), these two measures are effectively our preferred productivity measure plus some variables carrying additional scope for measurement error. ${ }^{36}$ That is, in the light of a Ricardian model, it is natural that column

\footnotetext{
${ }^{34}$ This finding echoes the work of Morrow (2009).

${ }^{35}$ These alternative productivity proxies are reported in the GDDC database and are constructed in a standard fashion. That is, real gross output per worker is constructed as the nominal value of gross output per worker in an exporter-industry divided by the producer price index and 'primal' TFP is calculated as $\ln T F P_{i}^{k}=\ln Y_{i}^{k}-\alpha_{i K}^{k} \ln K_{i}^{k}-\alpha_{i L}^{k} \ln L_{i}^{k}-\alpha_{i M}^{k} \ln M_{i}^{k}$, where $Y_{i}^{k}, K_{i}^{k}, L_{i}^{k}$ and $M_{i}^{k}$ represent real values of gross output, capital, labor and intermediate inputs respectively (where these real values are computed as the ratio of nominal values over the relevant price index), and the $\alpha$ terms represent income shares.

${ }^{36}$ Consider the example of real gross output per worker, a productivity measure that has been used extensively in the empirical Ricardian literature. This variable is computed as nominal gross output per worker divided by a producer price index (i.e., by our preferred productivity measure). Since nominal gross output per worker should be equal - in our Ricardian setting - to the nominal wage which is equal across sectors, any divergence between relative real gross output per worker and relative (inverse) producer prices
} 
1 contains a larger estimate of $\theta$ than columns 3 and 4 because it is based on the measure of productivity that is least likely to be mismeasured.

4.4. Alternative Samples. In this section we explore the extent to which our estimate of $\theta=6.53$, obtained above, is robust to a number of alternative samples. The first sample restriction we consider is to country- pairs in the EU only, which we use to test how our results depend on our assumption of orthogonality between relative trade costs and relative productivity. The second set of sample restrictions we consider is to observations for which we have increased confidence that producer prices were collected in a manner consistent with our theory. In all of these sample restrictions our estimate of $\theta$ is reassuringly robust (varying from 4.62 to 8.06 ) and within the bounds of previous estimates in the literature.

\subsubsection{Endogenous Trade Protection. In Section 4.2, we have described two potential sources} of bias of our OLS estimates and discussed how they could be addressed by an IV strategy. This IV strategy, however, does not obviate issues related to endogenous trade protection, which could bias our estimates downward. ${ }^{37}$ In order to address this issue, we now estimate Equation (17) again by IV but on a sample that includes EU exporters and importers only. ${ }^{38}$

per worker must be due to measurement error in nominal output per worker (due to measurement error in nominal output or the number of workers).

${ }^{37}$ To see that our IV estimate of $\theta$ would be biased towards zero under endogenous trade protection, suppose, using again the more compact notation of Equation (16), that trade barriers, $d_{i j}^{k}$, and exports, $x_{i j}^{k}$, are simultaneously determined according to:

$$
\begin{aligned}
& \ln \left(\frac{d_{i j}^{k} d_{i^{\prime} j^{\prime}}^{k^{\prime}}}{d_{i j}^{k^{\prime}} d_{i^{\prime} j^{\prime}}^{k}}\right)=\mu \ln \left(\frac{\widetilde{x}_{i j}^{k} \widetilde{x}_{i^{\prime} j}^{k^{\prime}}}{\widetilde{x}_{i j}^{k^{\prime}} \widetilde{x}_{i^{\prime} j}^{k}}\right), \\
& \ln \left(\frac{\widetilde{x}_{i j}^{k} \widetilde{x}_{i^{\prime} j}^{k^{\prime}}}{\widetilde{x}_{i j}^{k^{\prime}} \widetilde{x}_{i^{\prime} j}^{k}}\right)=\theta \ln \left(\frac{\widetilde{z}_{i}^{k} \widetilde{z}_{i^{\prime}}^{k^{\prime}}}{\widetilde{z}_{i}^{k^{\prime}} \widetilde{z}_{i}^{k}}\right)-\theta \ln \left(\frac{d_{i j}^{k} d_{i^{\prime} j^{\prime}}^{k^{\prime}}}{d_{i j}^{k^{\prime}} d_{i^{\prime} j^{\prime}}^{k}}\right),
\end{aligned}
$$

where $\mu>0$ captures the fact that higher levels of import penetration lead to higher levels of protection. The previous system implies $\ln \left(\frac{\widetilde{x}_{i j}^{k} \widetilde{x}_{i^{\prime} j}^{k^{\prime}}}{\widetilde{x}_{i j}^{k^{\prime}} \widetilde{x}_{i^{\prime} j}^{k}}\right)=\theta \ln \left(\frac{\widetilde{z}_{i}^{k} \widetilde{z}_{i^{\prime}}^{k^{\prime}}}{\widetilde{z}_{i}^{k^{\prime}} \widetilde{z}_{i}^{k}}\right)+\ln \left(\frac{\varepsilon_{i j}^{k} \varepsilon_{i^{\prime} j^{\prime}}^{k^{\prime}}}{\varepsilon_{i j}^{k^{\prime}} \varepsilon_{i^{\prime} j^{\prime}}^{k}}\right)$ where $\ln \left(\frac{\varepsilon_{i j}^{k} \varepsilon_{i^{\prime} j^{\prime}}^{k^{\prime}}}{\varepsilon_{i j}^{k^{\prime}} \varepsilon_{i^{\prime} j^{\prime}}^{k}}\right)=-\theta \ln \left(\frac{d_{i j}^{k} d_{i^{\prime} j^{\prime}}^{k^{\prime}}}{d_{i j}^{k^{\prime}} d_{i^{\prime} j^{\prime}}^{k}}\right)=$ $-(1+\mu \theta)^{-1} \mu \theta^{2} \ln \left(\frac{\widetilde{z}_{i}^{k} \widetilde{z}_{i^{\prime}}^{k^{\prime}}}{\widetilde{z_{i}} \widetilde{z}_{i}^{k^{\prime}}}\right)$. If $\ln \left(\frac{\widetilde{z}_{i}^{k} \widetilde{z}_{i^{\prime}}^{k^{\prime}}}{\widetilde{z}_{i}^{k^{\prime}} \widetilde{z}_{i^{\prime}}^{k}}\right)=\beta \ln \left(\frac{R_{i}^{k} R_{i^{\prime}}^{k^{\prime}}}{R_{i}^{k^{\prime}} R_{i^{\prime}}^{k}}\right)$ with $\beta>0$, then $E\left[\ln \left(\frac{R_{i}^{k} R_{i^{\prime}}^{k^{\prime}}}{R_{i}^{k^{\prime}} R_{i^{\prime}}^{k}}\right) \cdot \ln \left(\frac{\varepsilon_{i j}^{k} \varepsilon^{k^{\prime} j^{\prime}}}{\varepsilon_{i j}^{k^{\prime}} \varepsilon_{i^{\prime} j^{\prime}}^{k}}\right)\right]=$ $-\beta \mu \theta^{2}(1+\mu \theta)^{-1} E\left[\left(\ln \left(\frac{\widetilde{z}_{i}^{k} \widetilde{z}_{i^{\prime}}^{k^{\prime}}}{\widetilde{z}_{i}^{k^{\prime}} \widetilde{z}_{i^{\prime}}^{k}}\right)\right)^{2}\right]<0$, leading to downward bias in the IV estimate of $\theta$.

${ }^{38}$ That is, we restrict the sample to exporting and importing countries that were in the European Economic Area in 1997: Belgium-Luxembourg, Denmark, Spain, Finland, France, Germany, Greece, Ireland, Italy, Netherlands, Portugal, Sweden and the UK. 


\section{Table 5: Cross-Sectional Results - Alternative Samples}

\begin{tabular}{|c|c|c|c|c|}
\hline & \multicolumn{4}{|c|}{ Dependent variable in all regressions: corrected exports } \\
\hline & $\begin{array}{c}\text { Entire } \\
\text { sample }\end{array}$ & $\begin{array}{c}\text { EU member } \\
\text { countries } \\
\text { only }\end{array}$ & $\begin{array}{c}\text { Producer } \\
\text { price data } \\
\text { below median } \\
\text { quality }\end{array}$ & $\begin{array}{c}\text { Producer } \\
\text { price data } \\
\text { above median } \\
\text { quality }\end{array}$ \\
\hline & $(1)$ & $(2)$ & (3) & (4) \\
\hline log (productivity based on producer prices) & $\begin{array}{c}6.534^{* * *} \\
(0.708)\end{array}$ & $\begin{array}{c}4.621^{\star \star \star} \\
(0.585)\end{array}$ & $\begin{array}{c}5.820^{\star \star *} \\
(1.106)\end{array}$ & $\begin{array}{c}8.057^{\star * \star} \\
(1.267)\end{array}$ \\
\hline Observations & 5,576 & 2,162 & 2,795 & 2,781 \\
\hline R-squared & 0.747 & 0.808 & 0.820 & 0.688 \\
\hline \multicolumn{5}{|c|}{$\begin{array}{l}\text { Notes: Regressions are based on estimating equation (17) using data from } 21 \text { countries and } 13 \text { manufacturing sectors } \\
\text { (listed in Table 1) in } 1997 \text {. All regressions instrument for productivity using log R\&D expenditures in 1997, and include } \\
\text { exporter-times-importer fixed effects and industry-times-importer fixed effects. 'Corrected exports' is the value of bilateral } \\
\text { exports divided by the share of the exporting country's absorption in the given industry that is sourced domestically (equal } \\
\text { to one minus the country and industry's import penetration ratio). 'Productivity based on producer prices' is the inverse of } \\
\text { the average producer price in an exporter-industry. 'Producer price data quality' is based on the percentage of underlying } \\
\text { price data observations w ithin the exporter-industry that were obtained (in the creation of the GGDC dataset) using } \\
\text { producer price data rather than expenditure price data. Data sources and construction are described in full in Section } 4.1 . \\
\text { Heteroskedasticity-robust standard errors are reported in parentheses. *** indicates statistically significantly different from } \\
\text { zero at the } 1 \% \text { level. }\end{array}$} \\
\hline
\end{tabular}

Within this free trade area there are no trade barriers and, hence, no scope for endogenous trade protection.

The results from restricting our sample to EU members are reported in column 2 of Table 5. Our preferred estimate of $\theta$ is reasonably stable to this sample restriction: it falls to 4.62 , which still lies within the $95 \%$ confidence interval of our previous estimate of 6.53 (reported again in column 1 of Table 5 for convenience) and remains statistically significant despite the reduction in sample size. It therefore appears that our estimates are unlikely to be biased due to endogenous trade protection.

4.4.2. Producer vs. Expenditure Prices. In an open economy, goods price data are only informative about domestic productivity differences to the extent that they reflect domestic 
producer rather than expenditure prices. Unfortunately, though most of the GGDC's internationally comparable price estimates are based on aggregations of micro-level observations of producer prices, in order to achieve a complete sample the GGDC were forced to include some observations of expenditure prices. Helpfully, however, the GGDC has published data on the share of raw price observations, within each country and industry, that were obtained from producer rather than expenditure accounts. ${ }^{39}$ We can therefore use this information to explore how our estimates change as we restrict our sample to the observations that are best suited to measuring producer productivity - namely, those that are drawn from underlying observations of producer rather than expenditure prices. In particular, we can rank the exporter-industry observations by the percentage of price data based on producer prices, and split our sample into groups of 'price data quality' based on this ranking.

Our previous results (in Tables 3 and 4 ) were based on the entire sample of price data. ${ }^{40}$ By contrast, column 3 of Table 5 reports IV results based on two different samples that are partitioned based on the quality of their producer price data-column 3 reports results for the sample that contains only exporter-industry observations with below-median price data quality and column 4 presents those with above-median price data quality. Our preferred estimate of $\theta$ is again reassuringly stable - given the standard errors on these estimates - to this sample truncation, changing from 6.53 (whole sample in column 1) to 5.82 (below-median quality sample in column 3) to 8.06 (above-median quality sample in column 4). Overall, we believe that the cluster of estimates of $\theta$ presented in Tables 4 and 5 adds considerable confidence to our preferred estimate of $\theta=6.53$.

4.5. Summary. What have we learned from the cross-sectional results in Tables 3-5? Our findings can be summarized as follows:

(1) Most importantly, the theoretical predictions of Theorem 3 are consistent with the data. That is, relative export levels across countries and industries, corrected for trade-driven selection, are positively correlated with relative productivity levels across countries and industries. Further, the correction procedure suggested by Theorem 3

\footnotetext{
${ }^{39}$ This information is tabulated in Appendix Tables 2 and 3 of Timmer, Ypma, and van Ark (2007). We have digitized the content of these tables so that it is included in the dataset used in the present paper.

${ }^{40}$ The median observation in the unrestricted sample, used in column 1 of Table 5 , is based on underlying price observations that are comprised of $84 \%$ producer prices and $16 \%$ expenditure prices.
} 
is quantitatively important: failure to correct export flows in this manner leads to bias that is both substantial (from 6.53 to 11.1), and in the direction suggested by our Ricardian model.

(2) Our preferred estimate of $\theta=6.53$ - which captures intra-industry heterogeneity à la Eaton and Kortum (2002) - is comfortably in line with previous estimates of this coefficient obtained in the literature, even though these estimates have been obtained using remarkably different methodologies.

(3) The difference between our OLS and IV estimates of $\theta$ suggests severe measurement error in international productivity levels, which should not be surprising given the well-known challenges of measuring internationally comparable productivity levels across countries and industries.

(4) Our estimate of $\theta$ is extremely similar, $\theta=6.70$, when using a productivity measure that strips out variation in factor intensity and factor prices across countries and industries, thereby giving support to the Ricardian interpretation of our results.

(5) Finally, our estimates of $\theta$ are robust to a number of sample restrictions that alleviate, among other things, concerns of bias due to endogenous trade protection.

Taken together these empirical results provide support for the ability of the Ricardian model to explain the pattern of trade across countries and industries. Comforted by such results, we go on to ask: In today's world trading system, how important - in a well-defined, welfare-based sense - are Ricardian forces?

\section{Counterfactual Results}

In order to investigate further the quantitative importance of productivity differences, we use Theorem 5 to ask the following counterfactual questions: What if, for any pair of exporters, there were no fundamental relative productivity differences across industries? What would be the consequences for aggregate trade flows and welfare? As mentioned earlier, we refer to this counterfactual exercise as 'Removing a country's Ricardian comparative advantage', though it is important to stress that in our model there are also Ricardian motives within each industry that our counterfactual exercise will leave intact.

5.1. Preliminary: Revealed Productivity. The formal procedure to compute our counterfactuals is as described in Section 3.3. However, to compute the initial productivity levels, 
$z_{i}^{k}$, that enter Equation (13) we do not to use producer price data from the GGDC Productivity Level Database, which, as argued in Section 4, suffer from severe measurement error. ${ }^{41}$ Instead, we use our model to obtain 'revealed' measures of productivity at the country and industry level. Formally, we estimate

$$
\ln x_{i j}^{k}=\delta_{i j}+\delta_{j}^{k}+\delta_{i}^{k}+\varepsilon_{i j}^{k},
$$

where $\delta_{i j}, \delta_{j}^{k}$, and $\delta_{i}^{k}$ are exporter-importer, importer-industry, and exporter-industry fixedeffects, respectively. According to our model, bilateral trade flows satisfy

$$
\ln x_{i j}^{k}=\delta_{i j}+\delta_{j}^{k}+\theta \ln z_{i}^{k}+\varepsilon_{i j}^{k}
$$

Hence estimates of $\delta_{i}^{k}$ can be used to construct revealed measures of productivity, $e^{\delta_{i}^{k} / \theta}$, in country $i$ and industry $k$. These measures, which will be used in all of our counterfactual procedures below, are reported in Table $6 .{ }^{42}$ As in Table 2, note that productivity levels have been normalized to one in all industries for the United States and in all countries for the Food industry. ${ }^{43}$

Before turning to our counterfactual results, it is worth pointing out that this simple way of computing revealed measures of productivity, while not the main focus of our paper, provides a theoretically-consistent alternative to Balassa's (1965) well-known index of 'revealed comparative advantage.' Like Balassa (1965), we offer a methodology that uses data on relative exports to infer the underlying pattern of comparative advantage across countries

\footnotetext{
${ }^{41}$ In Section 4, measurement error does not affect our IV estimates of $\theta$. Our IV strategy was precisely designed to overcome measurement error in productivity and obtain coefficient estimates that are purged of attenuation bias.

${ }^{42}$ Using revealed productivity measures does not alter our main results dramatically. If we use observed productivity (measured as inverse producer prices) projected on our instrumental variable (R\&D expenditure) our most important result, the world average welfare loss from moving 'removing a country's Ricardian comparative advantage,' is 2.3 percent rather than 5.5 percent of the total gains from trade. As in Section 5.3 , there also is considerable heterogeneity in this number across countries.

${ }^{43}$ Of course, our fixed-effect regression only identifies $\left(\delta_{i}^{k}-\delta_{i}^{k^{\prime}}\right)-\left(\delta_{i^{\prime}}^{k}-\delta_{i^{\prime}}^{k^{\prime}}\right)$, and therefore, $\left(\ln z_{i}^{k}-\ln z_{i}^{k^{\prime}}\right)-\left(\ln z_{i^{\prime}}^{k}-\ln z_{i^{\prime}}^{k^{\prime}}\right)$. These differences-in-differences, however, capture all of the essence of comparative advantage in our Ricardian model, and are all that is necessary for our counterfactual predictions; see Lemma 4 and Theorem 5.
} 
A QUANTITATIVE EXPLORATION OF RICARDO'S IDEAS

33

Table 6: Revealed Relative Productivity Levels, by Country and Industry

\begin{tabular}{|c|c|c|c|c|c|c|c|c|c|c|c|c|c|}
\hline & Food & $\begin{array}{l}\text { Tex- } \\
\text { tiles }\end{array}$ & Wood & Paper & Fuel & $\begin{array}{l}\text { Chem- } \\
\text { icals }\end{array}$ & Plastic & $\begin{array}{l}\text { Min- } \\
\text { erals }\end{array}$ & Metals & $\begin{array}{l}\text { Mach- } \\
\text { inery }\end{array}$ & $\begin{array}{l}\text { Elec- } \\
\text { trical }\end{array}$ & $\begin{array}{l}\text { Trans- } \\
\text { port }\end{array}$ & $\begin{array}{l}\text { Misc. } \\
\text { Manuf }\end{array}$ \\
\hline AUS & 1 & 0.91 & 0.72 & 0.63 & 0.74 & 0.76 & 0.74 & 0.69 & 0.88 & 0.71 & 0.72 & 0.68 & 0.77 \\
\hline BEL & 1 & 1.14 & 0.86 & 0.91 & 1.03 & 1.05 & 1.07 & 1.07 & 1.11 & 0.88 & 0.79 & 0.88 & 0.97 \\
\hline CZE & 1 & 1.35 & 1.15 & 1.07 & 0.93 & 1.05 & 1.21 & 1.55 & 1.40 & 1.11 & 0.89 & 1.08 & 1.22 \\
\hline DEN & 1 & 0.91 & 0.84 & 0.77 & 0.65 & 0.77 & 0.90 & 0.81 & 0.89 & 0.83 & 0.73 & 0.64 & 0.85 \\
\hline ESP & 1 & 1.13 & 0.85 & 0.87 & 0.81 & 0.87 & 1.03 & 1.15 & 1.08 & 0.84 & 0.76 & 0.96 & 0.94 \\
\hline FIN & 1 & 1.09 & 1.52 & 1.69 & 0.97 & 1.05 & 1.18 & 1.19 & 1.46 & 1.17 & 1.19 & 0.91 & 1.08 \\
\hline FRA & 1 & 1.07 & 0.82 & 0.91 & 0.96 & 0.97 & 1.00 & 1.05 & 1.07 & 0.87 & 0.84 & 0.90 & 0.89 \\
\hline GER & 1 & 1.21 & 0.96 & 1.05 & 0.98 & 1.07 & 1.19 & 1.16 & 1.25 & 1.08 & 0.97 & 1.08 & 1.03 \\
\hline GRE & 1 & 1.15 & 0.58 & 0.74 & 0.84 & 0.73 & 0.84 & 1.00 & 0.97 & 0.66 & 0.59 & 0.50 & 0.75 \\
\hline HUN & 1 & 1.13 & 0.89 & 0.85 & 0.78 & 0.90 & 0.99 & 1.06 & 1.07 & 0.83 & 0.88 & 0.85 & 0.83 \\
\hline IRE & 1 & 0.84 & 0.64 & 1.09 & 0.60 & 1.01 & 0.86 & 0.76 & 0.83 & 0.74 & 0.94 & 0.57 & 0.81 \\
\hline ITA & 1 & 1.42 & 0.91 & 0.96 & 0.82 & 0.96 & 1.16 & 1.26 & 1.20 & 1.08 & 0.85 & 0.91 & 1.19 \\
\hline JPN & 1 & 1.50 & 0.87 & 1.30 & 1.10 & 1.66 & 1.82 & 1.72 & 1.73 & 1.77 & 1.78 & 1.89 & 1.70 \\
\hline KOR & 1 & 1.68 & 0.84 & 0.92 & 0.86 & 1.20 & 1.45 & 1.03 & 1.37 & 1.20 & 1.32 & 1.41 & 1.33 \\
\hline NED & 1 & 0.96 & 0.68 & 0.87 & 0.95 & 0.91 & 0.93 & 0.86 & 0.96 & 0.77 & 0.82 & 0.75 & 0.83 \\
\hline POL & 1 & 1.18 & 1.05 & 0.92 & 0.99 & 0.93 & 1.00 & 1.18 & 1.27 & 0.86 & 0.83 & 0.84 & 1.05 \\
\hline PTL & 1 & 1.54 & 1.31 & 1.03 & 0.79 & 0.88 & 1.05 & 1.30 & 1.06 & 0.89 & 0.90 & 0.96 & 0.93 \\
\hline SLK & 1 & 1.31 & 1.23 & 1.15 & 0.77 & 1.12 & 1.32 & 1.48 & 1.62 & 1.08 & 0.91 & 0.90 & 1.15 \\
\hline SWE & 1 & 1.14 & 1.36 & 1.39 & 1.16 & 1.09 & 1.24 & 1.15 & 1.40 & 1.14 & 1.09 & 1.04 & 1.12 \\
\hline UK & 1 & 1.15 & 0.74 & 1.03 & 1.08 & 1.01 & 1.07 & 1.08 & 1.13 & 0.95 & 0.95 & 0.93 & 0.99 \\
\hline USA & 1 & 1 & 1 & 1 & 1 & 1 & 1 & 1 & 1 & 1 & 1 & 1 & 1 \\
\hline
\end{tabular}

and industries. ${ }^{44}$ There are, however, two important differences between Balassa's (1965) approach and ours. First, our empirical strategy is theoretically grounded. The ranking of the OLS estimates of $\left(\delta_{U S}^{k}-\delta_{i}^{k}\right)$, for instance, is the empirical counterpart to the ranking of $\left(\ln z_{i}^{k}-\ln z_{U S}^{k}\right)$ in our model. By contrast, in our model Balassa's index would not, in general, provide a ranking of relative productivity levels. Second, our approach fundamentally

\footnotetext{
${ }^{44}$ In Balassa (1965), the revealed comparative advantage of country $i$ in industry $k$ is formally defined as $\left(x_{i W \text { orld }}^{k} / \sum_{k^{\prime}=1}^{K} x_{i \text { World }}^{k^{\prime}}\right) /\left(\sum_{i^{\prime}=1}^{I} x_{i^{\prime} \text { World }}^{k} / \sum_{i^{\prime}=1}^{I} \sum_{k^{\prime}=1}^{K} x_{i^{\prime} \text { World }}^{k^{\prime}}\right)$ where $x_{i \text { World }}^{k}$ are the total exports of country $i$ in industry $k$.
} 
is about the pair-wise comparisons across exporters and industries that are at the core of comparative advantage in a Ricardian world. Put simply, our fixed effects aim to uncover which of Portugal and England is the country relatively better at producing wine than cloth. They do not try to assess whether Portugal is good at producing wine compared to an intuitive but ad-hoc benchmark. Unlike Balassa (1965), we do not aggregate exports across countries and industries, which - according to our model - allows us to separate the impact of productivity differences from trade costs and demand differences.

5.2. Trade Flows. We first consider the impact of 'removing a country's Ricardian comparative advantage' on trade flows. For each country and industry, we compute changes in total exports (to all destination countries combined) using Equation (14). The first column of Table 7 describes the change in total exports for the reference country, i.e. the country whose productivity remains unchanged. The overall picture is clear: on average, total trade volumes change very little. This should not come as a surprise. By construction, wages, and hence GDP levels, are unchanged in the counterfactual equilibrium. Thus, total trade volumes, which are related to the dispersion of GDP levels across countries, do not change very much either on average.

Intuitively, the main impact of our counterfactual exercise should be on the share of inter-industry trade. If there were no trade costs and no differences in preferences across countries, then 'removing a country's Ricardian comparative advantage' would eliminate all inter-industry trade, i.e. trade would be balanced industry-by-industry. To explore this idea systematically, we use a linear transformation of the Grubel and Lloyd (1975) index. For each country $i$ and industry $k$, we compute $100 \times\left|\sum_{j \neq i}\left(x_{i j}^{k}-x_{j i}^{k}\right)\right| / \sum_{j \neq i}\left(x_{i j}^{k}+x_{j i}^{k}\right)$. If all trade were intra-industry trade, this index would be equal to zero. Conversely, if all trade were inter-industry trade, it would be equal to 100. In our data the mean value of this index is 26.9, which resonates with the well-known fact that the majority of trade among OECD countries is intra-industry when industries are measured at the 2-digit level.

The second column of Table 7 reports the change in the previous index averaged across all industries (weighted by total trade in each industry). As expected, the extent of interindustry trade goes down for most reference countries. Note, however, that: $(i)$ 'removing a country's Ricardian comparative advantage' never gets rid of all inter-industry trade; and (ii), inter-industry trade may actually go up for some countries after Ricardian comparative 


\section{Table 7: Counterfactual Results - Baseline}

\begin{tabular}{|c|c|c|c|c|}
\hline \multirow[b]{3}{*}{ Reference country: } & \multicolumn{4}{|c|}{ Outcome variable of interest: } \\
\hline & $\begin{array}{l}\% \text { change in } \\
\text { total exports }\end{array}$ & $\begin{array}{l}\text { change in } \\
\text { index of inter- } \\
\text { industry trade }\end{array}$ & $\begin{array}{l}\% \text { change in } \\
\text { welfare }\end{array}$ & $\begin{array}{l}\% \text { change in } \\
\text { welfare relative } \\
\text { to the total } \\
\text { gains from } \\
\text { trade }\end{array}$ \\
\hline & (1) & $(2)$ & (3) & (4) \\
\hline Australia & 18.53 & -23.90 & -2.91 & -39.21 \\
\hline Belgium \& Luxembourg & -1.72 & 4.47 & 0.68 & 2.53 \\
\hline Czech Republic & 3.89 & 6.05 & -0.10 & -1.08 \\
\hline Denmark & 0.59 & -2.85 & -0.43 & -2.36 \\
\hline Spain & 3.69 & -3.85 & -0.45 & -7.01 \\
\hline Finland & -5.67 & 2.00 & 0.04 & 0.46 \\
\hline France & 0.80 & -0.43 & -0.20 & -3.10 \\
\hline Germany & -2.10 & -7.97 & 0.14 & 2.20 \\
\hline Greece & 26.46 & -12.62 & -4.47 & -41.40 \\
\hline Hungary & 1.73 & -5.97 & -0.27 & -1.78 \\
\hline Ireland & -5.71 & -5.57 & 0.12 & 0.44 \\
\hline Italy & -4.76 & -9.54 & 0.14 & 2.69 \\
\hline Japan & -6.13 & -25.99 & 0.34 & 23.43 \\
\hline Korea & 2.68 & -10.12 & -0.45 & -9.83 \\
\hline Netherlands & 2.00 & -0.87 & -0.61 & -2.65 \\
\hline Poland & 12.33 & -22.30 & -1.69 & -23.20 \\
\hline Portugal & 8.47 & -14.10 & -0.97 & -9.63 \\
\hline Slovakia & 2.28 & 14.41 & 0.83 & 4.66 \\
\hline Sweden & -2.99 & 3.22 & 0.36 & 3.56 \\
\hline United Kingdom & 3.47 & -4.06 & -0.27 & -3.10 \\
\hline United States & 3.82 & -3.19 & -0.43 & -11.87 \\
\hline World Average & 2.94 & -5.87 & -0.51 & -5.53 \\
\hline
\end{tabular}

Notes: Results from counterfactual calculations in which, one at a time for each country listed (the 'reference country'), every other country in the world is given the reference country's relative productivity levels across industries, while adjusting each country's absolute productivity levels in such a way as to hold nominal wages fixed around the world (so as to neutralize terms-of-trade effects). The methodology follows Lemma 4 and Theorem 5. Column (1) reports the resulting proportional change in the total volume of the reference country's exports. Column (2) reports the resulting change in the reference country's index of inter-industry trade (given in Section 5.2); this index takes the value of 100 in the case of pure inter-industry trade, and zero in the case of pure intra-industry trade. Column (3) reports the resulting proportional change in w elfare (equal to real income spent on manufacturing) for the reference country; a negative number indicates a w elfare loss. And Column (4) reports this change in welfare as a percentage of the total gains from trade; a negative number indicates a w elfare loss (and a value of -100 means that this loss is equal to that of moving to autarky). The row labeled 'World Average' reports the unw eighted average of the country-specific results above. 
advantage has been removed. Two simple explanations for these patterns are the existence of heterogeneous trade costs and heterogeneous preferences across countries in practice. We will come back to both of these explanations in detail below, while investigating the importance of Ricardian comparative advantage for welfare.

5.3. Welfare. To assess the welfare importance of Ricardian comparative advantage at the industry level, we now compute changes in welfare in the reference country using Equation (15). The last two columns of Table 7 present the change in welfare associated with removing Ricardian comparative advantage at the industry level. Seen through the lens of our Ricardian model, eliminating relative industry-level productivity differences across countries leads, on average, to a $0.5 \%$ decrease of real income (spent on manufacturing), or only a $5.5 \%$ decrease in the overall gains from trade. ${ }^{45}$

This small average effect, however, masks a tremendous amount of heterogeneity across countries. Countries such as Australia and Greece appear to be strong beneficiaries of interindustry Ricardian motives for trade - they each see over a third of their total gains from trade eroded by our counterfactual scenario. For a few countries in our sample, however, the removal of Ricardian comparative advantage actually leads to a welfare gain! Two obvious candidates for explaining these surprising results - heterogeneous trade costs and heterogeneous tastes - were introduced briefly in Section 5.2. In a Ricardian model without trade costs and with identical, homothetic preferences across countries, removing differences in relative productivity should always lower trade and welfare. ${ }^{46}$ In general, however, removing such differences may very well increase both trade flows and welfare if relative productivity differences are initially correlated with trade costs or differences in preferences (such that

\footnotetext{
${ }^{45}$ Normalizing the welfare impact of Ricardian comparative advantage by the total gains from trade allows us to ignore considerations related to the size of the non-tradable sector, which would affect both in a proportional manner. The formula for the total gains from trade is a simple multi-sector extension of the formula used by Eaton and Kortum (2002). It can be found, for example, in Donaldson (2008).

${ }^{46}$ In the absence of intra-industry trade, removing relative productivity differences leads to autarky, which trivially lowers welfare. In the presence of intra-industry trade, as in our model, removing relative productivity differences no longer leads to autarky. Nevetherless, it is easy to check that holding nominal wages fixed around the world (as we do in our counterfactual procedure), eliminating relative productivity differences, and hence inter-industry trade, necessarily minimizes welfare in the country whose Ricardian comparative advantage has been removed.
} 


\section{Table 8: Counterfactual Results - Robustness}

\begin{tabular}{|c|c|c|c|c|}
\hline \multirow[b]{2}{*}{ Counterfactual scenario: } & \multicolumn{4}{|c|}{ Outcome variable of interest: } \\
\hline & $\begin{array}{l}\% \text { change in } \\
\text { total exports }\end{array}$ & $\begin{array}{l}\text { change in } \\
\text { index of inter- } \\
\text { industry trade } \\
\text { (2) }\end{array}$ & $\begin{array}{l}\text { \% change in } \\
\text { welfare } \\
\text { (3) }\end{array}$ & $\begin{array}{l}\% \text { change in } \\
\text { welfare relative } \\
\text { to the total } \\
\text { gains from } \\
\text { trade } \\
\text { (4) }\end{array}$ \\
\hline Baseline (as in Table 7) & 2.94 & -5.87 & -0.51 & -5.53 \\
\hline No preference differences & 2.69 & -5.39 & -1.58 & -11.76 \\
\hline No trade costs & 3.46 & -11.37 & -0.75 & -10.09 \\
\hline No preference diffs. or trade costs & 3.57 & -11.38 & -2.82 & -27.28 \\
\hline \multicolumn{5}{|c|}{$\begin{array}{l}\text { Notes: Results from counterfactual calculations in which, one at a time for each country listed (the 'reference } \\
\text { country'), every other country in the w orld is given the reference country's relative productivity levels across } \\
\text { industries, w hile adjusting each country's absolute productivity levels in such a way as to hold nominal wages fixed } \\
\text { around the w orld (so as to neutralize terms-of-trade effects). The methodology follow s Lemma } 4 \text { and Theorem } 5 \text {. } \\
\text { Column (1) reports the resulting proportional change in the total volume of the reference country's exports. Column } \\
\text { (2) reports the resulting change in the reference country's index of inter-industry trade (given in Section } 5.2 \text { ); this } \\
\text { index takes the value of } 100 \text { in the case of pure inter-industry trade, and zero in the case of pure intra-industry } \\
\text { trade. Column (3) reports the resulting proportional change in w elfare (equal to real income spent on } \\
\text { manufacturing) for the reference country; a negative number indicates a w elfare loss. And Column (4) reports this } \\
\text { change in w elfare as a percentage of the total gains from trade; a negative number indicates a loss (and a value of - } \\
100 \text { means that this loss is equal to that of moving to autarky). Unw eighted w orld average effects (averaging } \\
\text { across all reference countries) of such counterfactuals are reported. The methodology follows Lemma } 4 \text { and } \\
\text { Theorem } 5 \text {. The 'No preference differences' scenario calculates w orld expenditure shares across goods such that } \\
\text { these shares are identical across countries. The 'No trade costs' scenario calcuates trade flow s in such a way } \\
\text { that idiosyncratic trade cost differences are zero; see footnote } 47 \text { for details. }\end{array}$} \\
\hline
\end{tabular}

the initial scope for gains from trade due to productivity differences is offset by that due to trade costs or preference differences).

A simple way to investigate the quantitative importance of each of these two explanations is to redo our counterfactual exercises under the assumption that expenditure shares do not differ across countries, and that trade costs satisfy $d_{i j}^{k}=d_{i j} \cdot d_{j}^{k}$, which, as shown in Corollary 2 , implies that trade costs no longer affect the pattern of inter-industry trade. ${ }^{47}$ The results of

\footnotetext{
${ }^{47}$ Formally, in scenario $(i)$, we assume that shares of expenditures $\alpha_{j}^{k}$ in country $j$ and industry $k$ are equal to the world share of expenditure in industry $k$ (so that all countries have the same expenditure shares). And in scenario $(i i)$, we assume that trade flows are equal to $\ln x_{i j}^{k}=\delta_{i j}+\delta_{j}^{k}+\delta_{i}^{k}$; that is, we assume that
} 
our new counterfactuals are reported in Table 8. On average, the welfare impact of Ricardian comparative advantage as a fraction of the total gains from trade (reported in column 4 of Table 8) goes up from 5.5\% in our baseline scenario to: $(i) 11.8 \%$ in the absence of preference differences; ( $i i) 10.1 \%$ in the absence of trade costs violating $d_{i j}^{k}=d_{i j} \cdot d_{j}^{k}$; and $(i i i), 27.3 \%$ in the absence of both. The results of this extension for all countries are presented in Table A1 (in Appendix C). As expected, the welfare change only becomes negative for all countries under scenario $(\mathrm{iii})$ since only this scenario assumes a world in which the only source of comparative advantage is relative productivity differences.

The previous results point towards the importance of trade costs and demand differences for thinking about the consequences of technology diffusion. In a textbook Ricardian model, if China gets access to the United States's technology, then trade flows and welfare will fall in the United States; see e.g. Samuelson (2004). By contrast, in a world with trade costs and demand differences across countries, the exact same pattern of technology diffusion may very well increase both trade and welfare in both countries. While exploring this possibility further is not the focus of our paper, the results presented in Table 8 are consistent with this idea.

\section{Concluding Remarks}

The Ricardian model has long been perceived as a useful pedagogical tool with, ultimately, little empirical content. Over the last twenty years, the Heckscher-Ohlin model, which emphasizes the role of cross-country differences in factor endowments, has generated a considerable amount of empirical work; see e.g. Bowen, Leamer, and Sveikauskas (1987), Trefler (1993), Trefler (1995), Davis and Weinstein (2001), and Schott (2004). In contrast, the Ricardian model, which emphasizes productivity differences, has generated almost none.

The main reason for this lack of attention is not the existence of strong beliefs regarding the relative importance of factor endowments and technological considerations. Previous empirical work on the Heckscher-Ohlin model unambiguously shows that technology matters. It derives instead from the obvious mismatch between the real world and the extreme assumptions of the standard two-country Ricardian model. Although the deficiencies of the

the error term, $\varepsilon_{i j}^{k}$, in Equation (18) exists only due to measurement error in trade flows and should be disregarded in a counterfactual analysis that assumes $d_{i j}^{k}=d_{i j} \cdot d_{j}^{k}$. 
Ricardian model have not lead to the disappearance of technological considerations from the empirical literature, it has had a strong influence on how the relationship between technology and trade has been studied. In the empirical Heckscher-Ohlin-Vanek literature, the factor content of trade - rather than the commodity pattern of trade - remains the main variable of interest.

Building on the seminal work of Eaton and Kortum (2002), the present paper has developed a structural Ricardian model that puts productivity differences at the forefront of the analysis of a core question in international economics: What goods do countries trade? Using this model, we have estimated the impact of productivity differences on the pattern of trade across countries and industries without having to rely on bilateral comparisons inspired by a two-country model, unclear orthogonality conditions, ad-hoc measures of export performance, or measures of productivity that are systematically biased due to trade-driven selection - all of which are limitations of the existing empirical Ricardian literature.

Using trade and productivity data from 1997, we have estimated the key structural parameter of the model, $\theta$, which governs the elasticity with which increases in observed productivity levels, ceteris paribus, lead to increased exports. Our estimate of this elasticity, $\theta=6.53$, is positive (in agreement with our Ricardian theory), robust to alternative estimation procedures, and lies comfortably within the range of existing estimates in the literature, despite our novel method for obtaining it. Finally, we have used our model to quantify the importance of inter-industry Ricardian forces in today's world economy by measuring the welfare consequences of removing Ricardian comparative advantage at the industry level. According to our estimates, the disappearance of such forces would only lead, on average, to a $5.5 \%$ decrease in the total gains from trade.

\section{References}

Acemoglu, D., P. Antras, and E. Helpman (2007): "Contracts and Technology Adoption," The American Economic Review, 97(3), 916-943.

Al-NajJAR, N. (2004): "Aggregation and the Law of Large Numbers in Large Economies," Games and Economic Behavior, pp. 1-35.

Balassa, B. (1963): "An Empirical Demonstration of Comparative Cost Theory," The Review of Economics and Statistics, pp. 231-238. 
(1965): "Trade Liberalization and Revealed Comparative Advantage," The Manchester School of Economic and Social Studies, 33, 99-123.

BECK, T. (2003): "Financial Dependence and International Trade," Review of International Economics, 11, 296-316.

Bernard, A. B., J. Eaton, J. B. Jensen, and S. Kortum (2003): "Plants and Productivity in International Trade," The American Economic Review, pp. 1268-1290.

Bhagwati, J. (1964): "The Pure Theory of International Trade: A Survey," The Economic Journal, pp. 1-84.

Billingsley, P. (1995): Probability and Measure. John Wiley \& Sons, Inc.

Bowen, H. P., E. E. Leamer, and L. Sveikauskas (1987): "Multicountry, Multifactor Tests of the Factor Abundance Theory," The American Economic Review, pp. 791-809. Burstein, A., And J. Vogel (2010): "Globalization, Technology, and the Skill Premium," Unpublished Manuscript, Columbia University and UCLA.

Caliendo, L., and F. Parro (2009): "Estimates of the Trade and Welfare Effects of NAFTA," Unpublished Manuscript, University of Chicago.

Chor, D. (2008): "Unpacking Sources of Comparative Advantage: A Quantitative Approach," Working Papers 13-2008, Singapore Management University.

Costinot, A. (2005): "Three Essays on Institutions and Trade," Ph.D. Dissertation, Princeton University.

(2009): "On the Origins of Comparative Advantage," Journal of International Economics, 77(2), 255-264.

Costinot, A., and I. Komunjer (2007): "What Goods Do Countries Trade? New Ricardian Predictions," NBER Working Paper No. 13691.

Cuñat, A., And M. Melitz (2010): "Volatility, Labor Market Flexibility and Comparative Advantage," Journal of the European Economics Association, forthcoming.

Davidson, J. (1994): Stochastic Limit Theory. Oxford University Press, Oxford.

Davis, D. R. (1995): "Intra-Industry Trade: A Heckscher-Ohlin-Ricardo Approach," Journal of International Economics, 39(3-4), 201-226.

Davis, D. R., And D. E. Weinstein (2001): "An Account of Global Factor Trade," The American Economic Review, pp. 1423-1453. 
A QUANTITATIVE EXPLORATION OF RICARDO'S IDEAS

Deardorff, A. V. (1984): "Testing Trade Theories and Predicting Trade Flows," in Handbook of International Economics, ed. by R. W. Jones, and P. B. Kenen, vol. 1, pp. 467-517. Amsteram: North Holland.

Dekle, R., J. Eaton, and S. Kortum (2008): "Global Rebalancing with Gravity: Measuring the Burden of Adjustment," IMF Staff Papers, 55(3), 511-540.

Donaldson, D. (2008): "Railroads of the Raj: Estimating the Impact of Transportation Infrastructure," Unpublished Manuscript, MIT.

Dornbusch, R., S. Fischer, and P. Samuelson (1977): "Comparative Advantage, Trade, and Payments in a Ricardian Model with a Continuum of Goods," The American Economic Review, 67, 823-839.

Eaton, J., and S. Kortum (2002): "Technology, Geography, and Trade," Econometrica, $70,1741-1779$.

Foster, L., J. Haltiwanger, and C. Syverson (2008): "Reallocation, Firm Turnover, and Efficiency: Selection on Productivity or Profitability?," American Economic Review, 98(1), 394-425.

Golub, S. S., and C.-T. Hsieh (2000): "Classical Ricardian Theory of Comparative Advantage Revisited," Review of International Economics, pp. 221-234.

Griffith, R., S. Redding, and J. Van Reenen (2004): "Mapping the two faces of R\&D: productivity growth in a panel of OECD industries," The Review of Economics and Statistics, 86(4), 883Ü-895.

Harrigan, J. (1997a): "Cross-Country Comparisons of Industry Total Factor Productivity: Theory and Evidence," Federal Reserve Bank of New York Research Paper no. 9734.

- (1997b): "Technology, Factor Supplies, and International Specialization: Estimating the Neo-Classical Model," The American Economic Review, pp. 475-494.

- (2005): "Airplanes and Comparative Advantage," NBER working paper 11688.

Helpman, E., And P. R. KRugman (1985): Market Structure and Foreign Trade. MIT Press.

Jones, R. W. (1961): "Comparative Advantage and the Theory of Tariffs: A Multi-Country, Multi-Commodity Model," The Review of Economic Studies, 28(3), 161-175.

Jorgensen, D., And Z. Griliches (1967): "The Explanation of Productivty Change," Review of Economic Studies, 34 (3), 249-283. 
KerR, W. R. (2009): "Heterogeneous Technology Diffusion and Ricardian Trade Patterns," Unpublished Manuscript, Harvard Business School.

Leamer, E., And J. Levinsohn (1995): "International Trade Theory: The Evidence," in Handbook of International Economics, ed. by G. Grossman, and K. Rogoff, vol. 3, pp. 1139-1194. Elsevier Science, New York.

Levchenko, A. (2007): "Institutional Quality and International Trade," The Review of Economic Studies, 74(3), 791-819.

MacDougall, G. (1951): "British and American Exports: A Study Suggested by the Theory of Comparative Costs, Part I," Economic Journal, 61(244), 697-724.

Manova, K. (2008): "Credit Constraints, Equity Market Liberalizations and International Trade," Journal of International Economics, 76, 33-47.

Matsuyama, K. (2005): "Credit Market Imperfections and Patterns of International Trade and Capital Flows," Journal of the European Economic Association, pp. 714-723.

Morrow, P. (2009): "East is East and West is West: A Ricardian-Heckscher-Ohlin Model of Comparative Advantage," Unpublished manuscript, University of Toronto.

Nunn, N. (2007): "Relationship-Specificity, Incomplete Contracts, and the Pattern of Trade," Quarterly Journal of Economics, 122(2), 569-600.

Romalis, J. (2004): "Factor Proportions and the Structure of Commodity Trade," The American Economic Review, pp. 67-97.

Samuelson, P. A. (2004): "Where Ricardo and Mill Rebut and Confirm Arguments of Mainstream Economists Supporting Globalization," Journal of Economic Perspectives, $18(3)(3), 135-146$.

Schotт, P. (2004): “Across-Product versus Within-Product Specialization in International Trade," Quarterly Journal of Economics, pp. 647-678.

Shikher, S. (2004): "Putting Industries into the Eaton-Kortum Model," Unpublished Manuscript, Suffolk University.

(2008): "Predicting the effects of NAFTA: Now we can do it better!," Unpublished Manuscript, Suffolk University.

Simonovska, I., And M. E. Waugh (2009): "The Elasticity of Trade: Estimates and Evidence," Unpublished Manuscript, UC Davis and NYU. 
Stern, R. M. (1962): "British and American Productivity and Comparative Costs in International Trade," Oxford Economic Papers, pp. 275-303.

Timmer, M. P., G. YPma, and B. van ARK (2007): "PPPs for industry output: A new dataset for international comparisons," GGDC Research Memorandum GD-82, Groningen Growth and Development Centre.

Trefler, D. (1993): "International Factor Price Differences: Leontief was Right!," Journal of Political Economy, pp. 961-987.

_ (1995): "The Case of the Missing Trade and Other Mysteries," The American Economic Review, pp. 1029-1046.

Vogel, J. (2007): "Institutions and Moral Hazard in Open Economies," Journal of International Economics, 71(2), 495-514.

Wilson, C. A. (1980): "On the General Structure of Ricardian Models with a Continuum of Goods: Applications to Growth, Tariff Theory, and Technical Change," Econometrica, pp. $1675-1702$.

Yeaple, S., and S. S. Golub (2007): "International Productivity Differences, Infrastructure, and Comparative Advantage," Review of International Economics, 15(2), 223-242. 


\section{Appendix A: Proofs of Theorems 1-5}

Proof of Lemma 1. By Assumption A4, we know that bilateral trade flows satisfy

$$
\begin{aligned}
x_{i j}^{k} & =\frac{\sum_{\omega \in \Omega_{i j}^{k}}\left[p_{j}^{k}(\omega)\right]^{1-\sigma_{j}^{k}}}{\sum_{\omega \in \Omega} p_{j}^{k}(\omega)^{1-\sigma_{j}^{k}}} \cdot \alpha_{j}^{k} \mathrm{w}_{j} L_{j} \\
& =\frac{\sum_{\omega \in \Omega}\left[p_{j}^{k}(\omega) \mathbb{I}\left\{c_{i j}^{k}(\omega)=\min _{1 \leq i^{\prime} \leq I} c_{i^{\prime} j}^{k}(\omega)\right\}\right]^{1-\sigma_{j}^{k}}}{\sum_{\omega \in \Omega} p_{j}^{k}(\omega)^{1-\sigma_{j}^{k}}} \cdot \alpha_{j}^{k} \mathrm{w}_{j} L_{j}
\end{aligned}
$$

where the function $\mathbb{I}\{\cdot\}$ is the standard indicator function. By Assumption A1, $z_{i}^{k}(\omega)$ is independent and identically distributed (i.i.d.) across varieties so the same holds for $c_{i j}^{k}(\omega)$. In addition, $z_{i}^{k}(\omega)$ is i.i.d. across countries so $\mathbb{I}\left\{c_{i j}^{k}(\omega)=\min _{1 \leq i^{\prime} \leq I} c_{i^{\prime} j}^{k}(\omega)\right\}$ is i.i.d. across varieties as well. This implies that $p_{j}^{k}(\omega)^{1-\sigma_{j}^{k}}$ and $p_{j}^{k}(\omega)^{1-\sigma_{j}^{k}} \cdot \mathbb{I}\left\{c_{i j}^{k}(\omega)=\min _{1 \leq i^{\prime} \leq I} c_{i^{\prime} j}^{k}(\omega)\right\}$ are i.i.d. across varieties. Moreover, since $\sigma_{j}^{k}<1+\theta$ we have $E\left[p_{j}^{k}(\omega)^{1-\sigma_{j}^{k}}\right]<\infty$ so we can use the strong law of large numbers for i.i.d. random variables (e.g. Theorem 22.1 in Billingsley (1995) and the continuous mapping theorem (e.g. Theorem 18.10 (i) in Davidson (1994)) to show that

$$
x_{i j}^{k}=\frac{E\left[p_{j}^{k}(\omega)^{1-\sigma_{j}^{k}} \cdot \mathbb{I}\left\{c_{i j}^{k}(\omega)=\min _{1 \leq i^{\prime} \leq I} c_{i^{\prime} j}^{k}(\omega)\right\}\right]}{E\left[p_{j}^{k}(\omega)^{1-\sigma_{j}^{k}}\right]} \cdot \alpha_{j}^{k} \mathrm{w}_{j} L_{j} .
$$

Consider $H_{i j}^{k}\left(c_{1 j}^{k}, \ldots, c_{I j}^{k}\right) \equiv E\left[p_{j}^{k}(\omega)^{1-\sigma_{j}^{k}} \cdot \mathbb{I}\left\{c_{i j}^{k}(\omega)=\min _{1 \leq i^{\prime} \leq I} c_{i^{\prime} j}^{k}(\omega)\right\}\right]$. Assumptions A1, A3 and straightforward computations yield

$$
H_{i j}^{k}\left(c_{1 j}^{k}, \ldots, c_{I j}^{k}\right)=\int_{0}^{+\infty}\left(\frac{c_{i j}^{k}}{v}\right)^{1-\sigma_{j}^{k}} f(v)\left[\prod_{i^{\prime} \neq i} F\left(\frac{c_{i^{\prime} j}^{k}}{c_{i^{\prime} j}^{k}} v\right)\right] d v
$$

where $F_{i}^{k}(z)=F\left(z / z_{i}^{k}\right)$ and we let $f(u) \equiv F^{\prime}(u)$. Under the Fréchet Assumption A1, we have $F(z)=\exp \left(-z^{-\theta}\right)$ and $f(z)=\theta z^{-(\theta+1)} \exp \left(-z^{-\theta}\right)$.

Using Equation (19) together with the expressions for the Fréchet distribution and density, we then have

$$
\begin{aligned}
& E\left[p_{j}^{k}(\omega)^{1-\sigma_{j}^{k}} \cdot \mathbb{I}\left\{c_{i j}^{k}(\omega)=\min _{1 \leq i^{\prime} \leq I} c_{i^{\prime} j}^{k}(\omega)\right\}\right] \\
& =\int_{0}^{+\infty}\left(\frac{c_{i j}^{k}}{v}\right)^{1-\sigma_{j}^{k}} \frac{\theta}{v^{\theta+1}} \exp \left[-v^{-\theta} \sum_{i^{\prime}=1}^{I}\left(\frac{c_{i^{\prime} j}^{k}}{c_{i j}^{k}}\right)^{-\theta}\right] d v \\
& =\Gamma\left(\frac{\theta+1-\sigma_{j}^{k}}{\theta}\right) \frac{\left(c_{i j}^{k}\right)^{-\theta}}{\left[\sum_{i^{\prime}=1}^{I}\left(c_{i^{\prime} j}^{k}\right)^{-\theta}\right]^{\left(\theta+1-\sigma_{j}^{k}\right) / \theta}},
\end{aligned}
$$


where $\Gamma(\cdot)$ denotes the Gamma function, $\Gamma(t)=\int_{0}^{+\infty} v^{t-1} \exp (-v) d v$ for any $t>0$. Note that

$$
E\left[p_{j}^{k}(\omega)^{1-\sigma_{j}^{k}}\right]=\sum_{i=1}^{I} E\left[p_{j}^{k}(\omega)^{1-\sigma_{j}^{k}} \cdot \mathbb{I}\left\{c_{i j}^{k}(\omega)=\min _{1 \leq i^{\prime} \leq I} c_{i^{\prime} j}^{k}(\omega)\right\}\right],
$$

so that by using Equation (20) we get

$$
E\left[p_{j}^{k}(\omega)^{1-\sigma_{j}^{k}}\right]=\Gamma\left(\frac{\theta+1-\sigma_{j}^{k}}{\theta}\right) \frac{1}{\left[\sum_{i^{\prime}=1}^{I}\left(c_{i^{\prime} j}^{k}\right)^{-\theta}\right]^{\left(1-\sigma_{j}^{k}\right) / \theta}}
$$

and hence

$$
x_{i j}^{k}=\frac{\left(c_{i j}^{k}\right)^{-\theta}}{\sum_{i^{\prime}=1}^{I}\left(c_{i^{\prime} j}^{k}\right)^{-\theta}} \cdot \alpha_{j}^{k} \mathrm{w}_{j} L_{j} .
$$

With iceberg trade costs, Assumption A2, we have $c_{i j}^{k}=d_{i j}^{k} \mathrm{w}_{i} / z_{i}^{k}$. Combining the previous expression with Equation (21) gives the result of Lemma 1.

Proof of Theorem 3. We make use of the following Lemma:

Lemma 6. Suppose that the triangular inequality in Assumption A2 holds. Then, for all countries $i$ and goods $k$,

$$
\Omega_{i}^{k}=\left\{\omega \mid c_{i i}^{k}(\omega)=\min _{1 \leq i^{\prime} \leq I} c_{i^{\prime} i}^{k}(\omega)\right\}
$$

Proof of Lemma 6. We proceed by contradiction. Fix an exporter $j$, and suppose there exists a variety $\omega_{0}$ of $\operatorname{good} k$ and a country $l \neq j$ such that:

$$
\left\{\begin{array}{c}
c_{j l}^{k}\left(\omega_{0}\right)=\min _{1 \leq i^{\prime} \leq I} c_{i^{\prime} l}^{k}\left(\omega_{0}\right) \\
c_{j j}^{k}\left(\omega_{0}\right) \neq \min _{1 \leq i^{\prime} \leq I} c_{i^{\prime} j}^{k}\left(\omega_{0}\right)
\end{array}\right.
$$

Then, there must be an exporter $i \neq j$ such that

$$
\left\{\begin{array}{l}
d_{j l}^{k} \cdot \mathrm{w}_{j} / z_{j}^{k}\left(\omega_{0}\right) \leq d_{i l}^{k} \cdot \mathrm{w}_{i} / z_{i}^{k}\left(\omega_{0}\right) \\
d_{j j}^{k} \cdot \mathrm{w}_{j} / z_{j}^{k}\left(\omega_{0}\right)>d_{i j}^{k} \cdot \mathrm{w}_{i} / z_{i}^{k}\left(\omega_{0}\right)
\end{array}\right.
$$

Since $d_{j j}^{k}=1$, taking the ratio of the two inequalities above gives

$$
d_{i l}^{k}>d_{i j}^{k} \cdot d_{j l}^{k}
$$

which contradicts Assumption A2. This completes the proof of Lemma 6.

Proof of Theorem 3 (continued). By definition, we know that $c_{i i}^{k}(\omega)=d_{i i}^{k} \mathrm{w}_{i} / z_{i}^{k}(\omega)$. Using Lemma 6 then yields

$$
\widetilde{z}_{i}^{k} \equiv E\left[z_{i}^{k}(\omega) \mid \omega \in \Omega_{i}^{k}\right]=\frac{G_{i i}\left(c_{1 i}^{k}, \ldots, c_{I i}^{k}\right)}{\theta_{i i}^{k}} \cdot d_{i i}^{k} \mathrm{w}_{i},
$$


where we have let

$$
\begin{aligned}
G_{i i}\left(c_{1 i}^{k}, \ldots, c_{I i}^{k}\right) & \equiv E\left[\left(c_{i i}^{k}(\omega)\right)^{-1} \mathbb{I}\left\{c_{i i}^{k}(\omega)=\min _{1 \leq i^{\prime} \leq I} c_{i^{\prime} i}^{k}(\omega)\right\}\right] \\
\theta_{i i}^{k} & \equiv \operatorname{Pr}\left\{c_{i i}^{k}(\omega)=\min _{1 \leq i^{\prime} \leq I} c_{i^{\prime} i}^{k}(\omega)\right\} .
\end{aligned}
$$

The expressions for $G_{i i}\left(c_{1 i}^{k}, \ldots, c_{I i}^{k}\right)$ and $\theta_{i i}^{k}$ can easily be computed from the expression for $H_{i i}^{k}\left(c_{1 i}^{k}, \ldots, c_{I i}^{k}\right)$ in proof of Lemma 1 when the result in Equation (20) is evaluated at $\sigma_{i}^{k}=2$ and $\sigma_{i}^{k}=1$, respectively. By Equation (20), we formally have

$$
\begin{aligned}
G_{i i}\left(c_{1 i}^{k}, \ldots, c_{I i}^{k}\right) & =\Gamma\left(\frac{\theta-1}{\theta}\right) \frac{\left(c_{i i}^{k}\right)^{-\theta}}{\left[\sum_{i^{\prime}=1}^{I}\left(c_{i^{\prime} i}^{k}\right)^{-\theta}\right]^{(\theta-1) / \theta}} ; \\
\theta_{i i}^{k} & =\Gamma(1) \frac{\left(c_{i i}^{k}\right)^{-\theta}}{\sum_{n=1}^{I}\left(c_{i^{\prime} i}^{k}\right)^{-\theta}} .
\end{aligned}
$$

Hence,

$$
\widetilde{z}_{i}^{k}=\Gamma\left(\frac{\theta-1}{\theta}\right) \frac{1}{\left[\sum_{i^{\prime}=1}^{I}\left(c_{i^{\prime} i}^{k}\right)^{-\theta}\right]^{-1 / \theta}} \cdot d_{i i}^{k} \mathrm{w}_{i}=z_{i}^{k} \cdot \Gamma\left(\frac{\theta-1}{\theta}\right)\left[\frac{\left(c_{i i}^{k}\right)^{-\theta}}{\sum_{i^{\prime}=1}^{I}\left(c_{i^{\prime} i}^{k}\right)^{-\theta}}\right]^{-1 / \theta}
$$

Now, recall that we have defined $\pi_{i i}^{k} \equiv x_{i i}^{k} /\left[\sum_{i^{\prime}=1}^{I} x_{i^{\prime} i}^{k}\right]$. Using the expression for $x_{i j}^{k}$ obtained in (21) it then follows that under the Fréchet assumption A1 we have:

$$
\pi_{i i}^{k}=\frac{\left(c_{i i}^{k}\right)^{-\theta}}{\sum_{n=1}^{I}\left(c_{i^{\prime} i}^{k}\right)^{-\theta}}=\theta_{i i}^{k} .
$$

Combining the two previous equations, we obtain

$$
\widetilde{z}_{i}^{k}=z_{i}^{k} \cdot \Gamma\left(\frac{\theta-1}{\theta}\right)\left(\pi_{i i}^{k}\right)^{-1 / \theta}
$$

Now, from Equation (21), we know that for every $i$ and $j$,

$$
x_{i j}^{k}=\frac{\left(d_{i j}^{k} \mathrm{w}_{i} / z_{i}^{k}\right)^{-\theta}}{\sum_{i^{\prime}=1}^{I}\left(d_{i^{\prime} j}^{k} \mathrm{w}_{i^{\prime}} / z_{i^{\prime}}^{k}\right)^{-\theta}} \cdot \alpha_{j}^{k} \mathrm{w}_{j} L_{j}
$$

so combining with (25) and using $\widetilde{x}_{i j}^{k}=x_{i j}^{k} / \pi_{i i}^{k}$ gives

$$
\widetilde{x}_{i j}^{k}=\left[\Gamma\left(\frac{\theta-1}{\theta}\right)\right]^{-\theta} \frac{\left(d_{i j}^{k} \mathrm{w}_{i} / \widetilde{z}_{i}^{k}\right)^{-\theta}}{\sum_{i^{\prime}=1}^{I}\left(d_{i^{\prime} j}^{k} \mathrm{w}_{i^{\prime}} / z_{i^{\prime}}^{k}\right)^{-\theta}} \cdot \alpha_{j}^{k} \mathrm{w}_{j} L_{j} .
$$

Analogously to Lemma 1, the result of Theorem 3 then follows.

Proof of Lemma 4. Throughout this proof, we use $\mathrm{w}_{i_{0}}$ as our numeraire in the initial and counterfactual trade equilibrium: $\mathrm{w}_{i_{0}}=\left(\mathrm{w}_{i_{0}}\right)^{\prime}=1$. By definition, we know that $Z_{i}$ is chosen for any $i \neq i_{0}$ such that the value of the relative wage $\left(\mathrm{w}_{i} / \mathrm{w}_{i_{0}}\right)^{\prime}$ in the counterfactual equilibrium is the same as in the initial equilibrium $\left(\mathrm{w}_{i} / \mathrm{w}_{i_{0}}\right)$. Thus Assumption A5 implies

$$
\sum_{j=1}^{I} \sum_{k=1}^{K}\left(\pi_{i j}^{k}\right)^{\prime} \alpha_{j}^{k} \mathrm{w}_{j} L_{j}=\mathrm{w}_{i} L_{i},
$$


where $\left(\pi_{i j}^{k}\right)^{\prime}$ are the exports from country $i$ in country $j$ and industry $k$ in the counterfactual equilibrium. Using the expression for $\left(c_{i j}^{k}\right)^{\prime}=\left(\mathrm{w}_{i}\right)^{\prime} d_{i j}^{k} /\left(z_{i}^{k}\right)^{\prime}$, Equation (24) implies

$$
\left(\pi_{i j}^{k}\right)^{\prime}=\frac{\left[\left(\mathrm{w}_{i}\right)^{\prime} d_{i j}^{k} /\left(z_{i}^{k}\right)^{\prime}\right]^{-\theta}}{\sum_{n=1}^{I}\left[\left(\mathrm{w}_{i^{\prime}}\right)^{\prime} d_{i^{\prime} j}^{k} /\left(z_{i^{\prime}}^{k}\right)^{\prime}\right]^{-\theta}} .
$$

Combining the above with the expression for $\pi_{i j}^{k}$ and using the fact that the relative wages remain unchanged in the counterfactual equilibrium, we get after rearrangements

$$
\left(\pi_{i j}^{k}\right)^{\prime}=\frac{\left[\left(z_{i}^{k}\right)^{\prime} / z_{i}^{k}\right]^{\theta}}{\sum_{i^{\prime}=1}^{I}\left[\left(z_{i^{\prime}}^{k}\right)^{\prime} / z_{i^{\prime}}^{k}\right]^{\theta} \pi_{i^{\prime} j}^{k}} \cdot \pi_{i j}^{k}=\frac{\left(z_{i_{0}}^{k}\right)^{\theta} Z_{i}^{\theta}\left(z_{i}^{k}\right)^{-\theta}}{\sum_{i^{\prime}=1}^{I}\left(z_{i_{0}}^{k}\right)^{\theta} Z_{i^{\prime}}^{\theta}\left(z_{i^{\prime}}^{k}\right)^{-\theta} \pi_{i^{\prime} j}^{k}} \cdot \pi_{i j}^{k},
$$

where the second equality uses the definition of $Z_{i}$ in Equation (??). Taken together, Equations (26) and (27) imply

$$
\sum_{j=1}^{I} \sum_{k=1}^{K} \frac{\left(z_{i}^{k} / Z_{i}\right)^{-\theta} \pi_{i j}^{k} \alpha_{j}^{k} \gamma_{j}}{\sum_{i^{\prime}=1}^{I}\left(z_{i^{\prime}}^{k} / Z_{i^{\prime}}\right)^{-\theta} \pi_{i^{\prime} j}^{k}}=\gamma_{i}
$$

where $\gamma_{i} \equiv \mathrm{w}_{i} L_{i} / \sum_{j=1}^{I} \mathrm{w}_{j} L_{j}$ is the share of country $i$ in world income in the initial equilibrium.

Proof of Theorem 5. Similar to previously and throughout this proof, we use $\mathrm{w}_{i_{0}}$ as our numeraire in the initial and counterfactual trade equilibrium: $\mathrm{w}_{i_{0}}=\left(\mathrm{w}_{i_{0}}\right)^{\prime}=1$.

1. Counterfactual changes in bilateral trade flows, $x_{i j}^{k}$.

By Equation (21), we know that

$$
\left(x_{i j}^{k}\right)^{\prime}=\frac{\left(\left(\mathrm{w}_{i}\right)^{\prime} d_{i j}^{k} /\left(z_{i}^{k}\right)^{\prime}\right)^{-\theta}}{\sum_{i^{\prime}=1}^{I}\left(\left(\mathrm{w}_{i^{\prime}}\right)^{\prime} d_{i^{\prime} j}^{k} /\left(z_{i^{\prime}}^{k}\right)^{\prime}\right)^{-\theta}} \cdot \alpha_{j}^{k}\left(\mathrm{w}_{j}\right)^{\prime} L_{j} .
$$

Combining the above with the expression for $\hat{x}_{i j}^{k}=\left(x_{i j}^{k}\right)^{\prime} / x_{i j}^{k}$ and using the fact that the relative wages remain unchanged in the counterfactual equilibrium, we get after rearrangements

$$
\hat{x}_{i j}^{k}=\frac{\left(\left(z_{i}^{k}\right)^{\prime} / z_{i}^{k}\right)^{\theta}}{\sum_{i^{\prime}=1}^{I}\left(\left(z_{i^{\prime}}^{k}\right)^{\prime} / z_{i^{\prime}}^{k}\right)^{\theta} \pi_{i^{\prime} j}^{k}}=\frac{\left(z_{i}^{k} / Z_{i}\right)^{-\theta}}{\sum_{i^{\prime}=1}^{I} \pi_{i^{\prime} j}^{k}\left(z_{i^{\prime}}^{k} / Z_{i^{\prime}}\right)^{-\theta}} .
$$

2. Counterfactual changes in country $i_{0}$ 's welfare, $W_{i_{0}} \equiv \mathrm{w}_{i_{0}} / p_{i_{0}}$.

Recall that by definition

$$
p_{i_{0}}^{k}=\left\{E\left[\sum_{\omega^{\prime} \in \Omega} p_{i_{0} j}^{k}\left(\omega^{1-\sigma_{j}^{k}}\right)\right]\right\}^{1 /\left(1-\sigma_{j}^{k}\right)},
$$

so from the proof of Theorem 1 we know that

$$
p_{i_{0}}^{k}=\left[\Gamma\left(\frac{\theta+1-\sigma_{j}^{k}}{\theta}\right)\right]^{1 /\left(1-\sigma_{j}^{k}\right)}\left[\sum_{i=1}^{I}\left(\mathrm{w}_{i} d_{i i_{0}}^{k} / z_{i}^{k}\right)^{-\theta}\right]^{-1 / \theta} .
$$


Given our adjustment in labor productivity, we also know that $\left(\mathrm{w}_{i}\right)^{\prime}=\mathrm{w}_{i}$ for all $i$. Thus

$$
\left(p_{i_{0}}^{k}\right)^{\prime}=\left[\Gamma\left(\frac{\theta+1-\sigma_{j}^{k}}{\theta}\right)\right]^{1 /\left(1-\sigma_{j}^{k}\right)}\left[\sum_{i=1}^{I}\left(\mathrm{w}_{i} d_{i i_{0}}^{k} /\left(z_{i}^{k}\right)^{\prime}\right)^{-\theta}\right]^{-1 / \theta} .
$$

Combining the two previous expressions with the definition of $\hat{p}_{i_{0}}^{k}=\left(p_{i_{0}}^{k}\right)^{\prime} / p_{i_{0}}^{k}$, we obtain

$$
\widehat{p}_{i_{0}}^{k}=\left[\sum_{i=1}^{I} \pi_{i i_{0}}^{k}\left(\frac{z_{i}^{k}}{z_{i_{0}}^{k} Z_{i}}\right)^{-\theta}\right]^{-1 / \theta} .
$$

By definition of $p_{i_{0}} \equiv \prod_{k=1}^{K}\left(p_{i_{0}}^{k}\right)^{\alpha_{i_{0}}^{k}}$, we therefore have

$$
\widehat{p}_{i_{0}}=\prod_{k=1}^{K}\left[\sum_{i=1}^{I} \pi_{i i_{0}}^{k}\left(\frac{z_{i}^{k}}{z_{i_{0}}^{k} Z_{i}}\right)^{-\theta}\right]^{-\alpha_{i_{0}}^{k} / \theta},
$$

which immediately implies Equation (15). 


\section{Appendix B: Robustness}

The objective of this Appendix is to investigate the robustness of our results to weaker supply-side assumptions. Instead of Assumptions A1, we now assume that:

A1'. For all countries $i$, goods $k$, and their varieties $\omega, z_{i}^{k}(\omega)$ is a random variable drawn independently for each triplet $(i, k, \omega)$ from a distribution $F_{i}^{k}(\cdot)$ such that:

$$
F_{i}^{k}(z)=F\left(\frac{z}{z_{i}^{k}}\right)
$$

where $F(\cdot)$ is a distribution on $[0,+\infty)$ with a continuous density $f(\cdot)$.

Compared to Assumptions $A 1, A 1^{\prime}$ does not impose any functional-form restriction on the distribution of productivities, $F(\cdot)$. Using this weaker assumption, we now derive local versions of Lemma 1, Theorem 3, and Theorem 5.

Lemma 7. Suppose that Assumptions A1'-A4 hold and that cost differences across exporters are small: $c_{1 j}^{k} \simeq \ldots \simeq c_{I j}^{k}$ for all $j$ and $k$. Then for any importer, $j$, any pair of exporters, $i$ and $i^{\prime}$, and any pair of goods, $k$ and $k^{\prime}$, there exists $\beta>0$ such that

$$
\ln \left(\frac{x_{i j}^{k} x_{i^{\prime} j}^{k^{\prime}}}{x_{i j}^{k^{\prime}} x_{i^{\prime} j}^{k}}\right) \simeq \beta \ln \left(\frac{z_{i}^{k} z_{i^{\prime}}^{k^{\prime}}}{z_{i}^{k^{\prime}} z_{i^{\prime}}^{k}}\right)-\beta \ln \left(\frac{d_{i j}^{k} d_{i^{\prime} j}^{k^{\prime}}}{d_{i j}^{k^{\prime}} d_{i^{\prime} j}^{k}}\right),
$$

Proof of Lemma \%. We have already established in the proof of Lemma 1 that bilateral trade flows can be expressed as

$$
\begin{aligned}
x_{i j}^{k} & =\frac{E\left[p_{j}^{k}(\omega)^{1-\sigma_{j}^{k}} \cdot \mathbb{I}\left\{c_{i j}^{k}(\omega)=\min _{1 \leq i^{\prime} \leq I} c_{i^{\prime} j}^{k}(\omega)\right\}\right]}{E\left[p_{j}^{k}(\omega)^{1-\sigma_{j}^{k}}\right]} \cdot \alpha_{j}^{k} \mathrm{w}_{j} L_{j} \\
& =\frac{H_{i j}\left(c_{1 j}^{k}, \ldots, c_{I j}^{k}\right)}{E\left[p_{j}^{k}(\omega)^{1-\sigma_{j}^{k}}\right]} \cdot \alpha_{j}^{k} \mathrm{w}_{j} L_{j},
\end{aligned}
$$

where we have let $H_{i j}\left(c_{1 j}^{k}, \ldots, c_{I j}^{k}\right) \equiv E\left[p_{j}^{k}(\omega)^{1-\sigma} \cdot \mathbb{I}\left\{c_{i j}^{k}(\omega)=\min _{1 \leq i^{\prime} \leq I} c_{i^{\prime} j}^{k}(\omega)\right\}\right]$. Similar to previously, Assumptions A1', A3 and straightforward computations yield

$$
H_{i j}\left(c_{1 j}^{k}, \ldots, c_{I j}^{k}\right)=\int_{0}^{+\infty}\left(\frac{c_{i j}^{k}}{v}\right)^{1-\sigma} f(v)\left[\prod_{i^{\prime} \neq i} F\left(\frac{c_{i^{\prime} j}^{k}}{c_{i^{\prime} j}^{k}} v\right)\right] d v .
$$

We now approximate $\ln \tilde{H}_{i j}\left(c_{1 j}^{k}, \ldots, c_{I j}^{k}\right) \equiv \ln H_{i j}\left(c_{1 j}^{k}, \ldots, c_{I j}^{k}\right)-(1-\sigma) \ln c_{i j}^{k}$ obtained from Equation (30) by its first order Taylor series around the symmetric case $\ln c_{1 j}^{k}=\ldots=\ln c_{I j}^{k}=\ln c$. Without loss of generality, we choose units of account in each industry $k$ such that $\ln c=0$. We have

$$
\left.\tilde{H}_{i j}\left(c_{1 j}^{k}, \ldots, c_{I j}^{k}\right)\right|_{(0, \ldots, 0)}=\int_{0}^{+\infty} v^{\sigma-1} f(v)[F(v)]^{I-1} d v
$$




$$
\left.\frac{\partial \tilde{H}_{i j}\left(c_{1 j}^{k}, \ldots, c_{I j}^{k}\right)}{\partial \ln c_{i j}^{k}}\right|_{(0, \ldots, 0)}=-(I-1) \int_{0}^{+\infty} v^{\sigma} f^{2}(v)[F(v)]^{I-2} d v
$$

and, for $i^{\prime} \neq i$,

$$
\left.\frac{\partial \tilde{H}_{i j}\left(c_{1 j}^{k}, \ldots, c_{I j}^{k}\right)}{\partial \ln c_{i^{\prime} j}^{k}}\right|_{(0, \ldots, 0)}=\int_{0}^{+\infty} v^{\sigma} f^{2}(v)[F(v)]^{I-2} d v
$$

Let

$$
\kappa \equiv \int_{0}^{+\infty} v^{\sigma-1} f(v)[F(v)]^{I-1} d v
$$

and

$$
\delta \equiv \kappa^{-1}\left[\int_{0}^{+\infty} v^{\sigma} f^{2}(v)[F(v)]^{I-2} d v\right] .
$$

Combining Equations (31), (32), and (33), we then get

$$
\begin{aligned}
\ln H_{i j}\left(c_{1 j}^{k}, \ldots, c_{I j}^{k}\right) & =\ln \kappa+(1-\sigma) \ln c_{i j}^{k}-(I-1) \delta \ln c_{i j}^{k}+\delta \sum_{i^{\prime} \neq i} \ln c_{i^{\prime} j}^{k}+o\left(\left\|\ln c_{j}^{k}\right\|\right) \\
& =\ln \kappa-(\delta I+\sigma-1) \ln c_{i j}^{k}+\delta \sum_{i^{\prime}=1}^{I} \ln c_{i^{\prime} j}^{k}+o\left(\left\|\ln c_{j}^{k}\right\|\right)
\end{aligned}
$$

where $\left\|\ln c_{j}^{k}\right\|^{2}=\sum_{i^{\prime}=1}^{I}\left[\ln c_{i^{\prime} j}^{k}\right]^{2}$ denotes the usual $L_{2}$-norm, and $\delta>0$ only depends on $f(\cdot), F(\cdot)$, $\sigma$ and $I$.

Combining Equation (34) with the definition of $c_{i j}^{k}=d_{i j}^{k} \cdot \mathrm{w}_{i} / z_{i}^{k}$ then gives

$$
\ln H_{i j}\left(c_{1 j}^{k}, \ldots, c_{I j}^{k}\right) \simeq \beta_{i}+b_{j}^{k}-\beta \ln \left(\frac{d_{i j}^{k}}{z_{i}^{k}}\right),
$$

where

$$
\begin{aligned}
\beta_{i} & \equiv \ln \kappa-(\delta I+\sigma-1) \ln \left(\mathrm{w}_{i}\right) \\
b_{j}^{k} & \equiv \delta \sum_{i^{\prime}=1}^{I} \ln c_{i^{\prime} j}^{k} \\
\beta & \equiv \delta I+\sigma-1
\end{aligned}
$$

Note that $\beta_{i}$ does not depend on the country $i$ and good $k$ indices, $b_{j}^{k}$ does not depend on the country index $i$, and $\beta>0$ is a positive constant which only depends on $f(\cdot), F(\cdot), \sigma$ and $I$. Combining Equation (35) with the expression for $x_{i j}^{k}$ then yields

$$
\ln x_{i j}^{k} \simeq \beta_{i}+\beta_{j}^{k}-\beta \ln \left(\frac{d_{i j}^{k}}{z_{i}^{k}}\right)
$$


where we have let $\beta_{j}^{k} \equiv \ln \left(\alpha_{j}^{k} \mathrm{w}_{j} L_{j}\right)+b_{j}^{k}-\ln E\left[p_{j}^{k}(\omega)^{1-\sigma}\right]$. Taking successive differences yields the result of Lemma 7 .

Theorem 8. Suppose that Assumptions A1'-A4 hold and that cost differences across exporters are small: $c_{1 j}^{k} \simeq \ldots \simeq c_{I j}^{k}$ for all $j, k$. Then for any importer $j$, any pair of exporters, $i$ and $i^{\prime}$, and any pair of goods, $k$ and $k^{\prime}$, there exist $\beta>0$ and $\zeta$ such that

$$
\ln \left(\frac{x_{i j}^{k} x_{i^{\prime} j}^{k^{\prime}}}{x_{i j}^{k^{\prime}} x_{i^{\prime} j}^{k}}\right) \simeq \beta \ln \left(\frac{\widetilde{z}_{i}^{k} \widetilde{z}_{i^{\prime}}^{k^{\prime}}}{\widetilde{z}_{i}^{k^{\prime}} \widetilde{z}_{i^{\prime}}^{k}}\right)-\beta \ln \left(\frac{d_{i j}^{k} d_{i^{\prime} j}^{k^{\prime}}}{d_{i j}^{k^{\prime}} d_{i^{\prime} j}^{k}}\right)+\zeta \ln \left(\frac{\pi_{i i}^{k} \pi_{i^{\prime} i^{\prime}}^{k^{\prime}}}{\pi_{i i}^{k^{\prime}} \pi_{i^{\prime} i^{\prime}}^{k}}\right) .
$$

Proof of Theorem 8. Recall from the proof of Theorem 3 that we have:

$$
\widetilde{z}_{i}^{k} \equiv E\left[z_{i}^{k}(\omega) \mid \omega \in \Omega_{i}^{k}\right]=\frac{G_{i i}\left(c_{1 i}^{k}, \ldots, c_{I i}^{k}\right)}{\theta_{i i}^{k}} \cdot d_{i i}^{k} \mathrm{w}_{i},
$$

where as before

$$
\begin{aligned}
G_{i i}\left(c_{1 i}^{k}, \ldots, c_{I i}^{k}\right) & =E\left[\left(c_{i i}^{k}(\omega)\right)^{-1} \mathbb{I}\left\{c_{i i}^{k}(\omega)=\min _{1 \leq i^{\prime} \leq I} c_{i^{\prime} i}^{k}(\omega)\right\}\right] ; \\
\theta_{i i}^{k} & =\operatorname{Pr}\left\{c_{i i}^{k}(\omega)=\min _{1 \leq i^{\prime} \leq I} c_{i^{\prime} i}^{k}(\omega)\right\} .
\end{aligned}
$$

Now, consider a first order Taylor development of $\ln G_{i i}\left(c_{1 i}^{k}, \ldots, c_{I i}^{k}\right)$ around $\ln c_{1 i}^{k}=\ldots=\ln c_{I i}^{k}=0$. The latter is readily available from the proof of Theorem 7: we only need to set $\sigma=2$ in the expression for $H_{i i}\left(c_{1 i}^{k}, \ldots, c_{I i}^{k}\right)$ obtained in Equation (34). By letting

$$
\lambda \equiv \int_{0}^{+\infty} v f(v)[F(v)]^{I-1} d v
$$

and

$$
\mu \equiv \lambda^{-1}\left[\int_{0}^{+\infty} v^{2} f^{2}(v)[F(v)]^{I-2} d v\right]
$$

we get

$$
\begin{aligned}
\ln G_{i i}\left(c_{1 i}^{k}, \ldots, c_{I i}^{k}\right) & =\ln \lambda-(\mu I+1) \cdot \ln c_{i i}^{k}+\mu \cdot \sum_{i^{\prime}=1}^{I} \ln c_{i^{\prime} i}^{k}+o\left(\left\|\ln c_{i}^{k}\right\|\right) \\
& =\ln \lambda-\ln c_{i i}^{k}+\mu \cdot \sum_{i^{\prime}=1}^{I} \ln \left(\frac{c_{i^{\prime} i}^{k}}{c_{i i}^{k}}\right)+o\left(\left\|\ln c_{i}^{k}\right\|\right)
\end{aligned}
$$

where $\|\cdot\|^{2}$ is the $L_{2}$-norm as previously. We can follow the same approach for $\ln \theta_{i i}^{k}$. By setting $\sigma=1$ in Equation (34), we get

$$
\begin{aligned}
\ln \theta_{i i}^{k} & =-\ln I-\tau \cdot I \cdot \ln c_{i i}^{k}+\tau \cdot \sum_{i^{\prime}=1}^{I} \ln c_{i^{\prime} i}^{k}+o\left(\left\|\ln c_{i}^{k}\right\|\right) \\
& =-\ln I+\tau \cdot \sum_{i^{\prime}=1}^{I} \ln \left(\frac{c_{i^{\prime} i}^{k}}{c_{i i}^{k}}\right)+o\left(\left\|\ln c_{i}^{k}\right\|\right),
\end{aligned}
$$


where

$$
\tau \equiv I \cdot\left[\int_{0}^{+\infty} v f^{2}(v)[F(v)]^{I-2} d v\right] .
$$

Combining Equation (37) with (38) and (39), we then obtain

$$
\ln \widetilde{z}_{i}^{k}=\ln (\lambda I)-\ln c_{i i}^{k}+\ln \left(d_{i i}^{k} \cdot \mathrm{w}_{i}\right)+(\mu-\tau) \sum_{i^{\prime}=1}^{I} \ln \left(\frac{c_{i^{\prime} i}^{k}}{c_{i i}^{k}}\right)+o\left(\left\|\ln c_{i}^{k}\right\|\right)
$$

which given that $c_{i i}^{k}=d_{i i}^{k} \cdot \mathrm{w}_{i} / z_{i}^{k}$ yields

$$
\ln \widetilde{z}_{i}^{k} \simeq \ln (\lambda I)+\ln z_{i}^{k}+(\mu-\tau) \sum_{i^{\prime}=1}^{I} \ln \left(\frac{c_{i^{\prime} i}^{k}}{c_{i i}^{k}}\right) .
$$

We now show that the last term can be written as a function of $\pi_{i i}^{k}=x_{i i}^{k} / \sum_{i^{\prime}=1}^{I} x_{i^{\prime} i}^{k}$ introduced previously. For this, fix any constant $\varphi$, and note that in the neighborhood of $\ln c_{1 i}^{k}=\ldots=\ln c_{I i}^{k}=0$ we have:

$$
\ln \left(\sum_{i^{\prime}=1}^{I}\left(\frac{c_{i^{\prime} i}^{k}}{c_{i i}^{k}}\right)^{-\varphi}\right)=\ln I+\frac{1}{I} \sum_{i^{\prime}=1}^{I}\left(\frac{c_{i^{\prime} i}^{k}}{c_{i i}^{k}}\right)^{-\varphi}-1+o\left(\left\|\ln c_{i}^{k}\right\|\right),
$$

and, in addition, for any $i^{\prime}$,

$$
\left(\frac{c_{i^{\prime} i}^{k}}{c_{i i}^{k}}\right)^{-\varphi}=1-\varphi \ln \left(\frac{c_{i^{\prime} i}^{k}}{c_{i i}^{k}}\right)+o\left(\left\|\ln c_{i}^{k}\right\|\right) .
$$

Combining the two equations above then shows that for any $\varphi$ :

$$
\sum_{i^{\prime}=1}^{I} \ln \left(\frac{c_{i^{\prime} i}^{k}}{c_{i i}^{k}}\right)=\frac{I}{\varphi}\left[\ln I-\ln \left(\sum_{i^{\prime}=1}^{I}\left(\frac{c_{i^{\prime} i}^{k}}{c_{i i}^{k}}\right)^{-\varphi}\right)\right]+o\left(\left\|\ln c_{i}^{k}\right\|\right) .
$$

Now, from the proof of Theorem 7 and its Equation (36) we know that

$$
\frac{x_{i^{\prime} i}^{k}}{x_{i i}^{k}}=\left(\frac{c_{i^{\prime} i}^{k}}{c_{i i}^{k}}\right)^{-\beta}\left[1+o\left(\left\|\ln c_{i}^{k}\right\|\right)\right],
$$

where $\beta$ is as defined in the proof of Theorem 7. Combining (42) with (41) evaluated at $\varphi=\beta$ we then get:

$$
\sum_{i^{\prime}=1}^{I} \ln \left(\frac{c_{i^{\prime} i}^{k}}{c_{i i}^{k}}\right)=\frac{I}{\beta}\left[\ln I+\ln \pi_{i i}^{k}\right]+o\left(\left\|\ln c_{i}^{k}\right\|\right),
$$

which when combined with (40) gives:

$$
\ln \widetilde{z}_{i}^{k} \simeq \ln (\lambda I)+\ln z_{i}^{k}+(\mu-\tau) \frac{I}{\beta}\left[\ln I+\ln \pi_{i i}^{k}\right] .
$$

Finally, we combine the above expression with (36) to get:

$$
\ln x_{i j}^{k} \simeq \beta_{i}+\beta_{j}^{k}-\beta \ln d_{i j}^{k}+\beta \ln \widetilde{z}_{i}^{k}+I(\tau-\mu) \ln \pi_{i i}^{k}-I \ln I(\mu-\tau)-\ln (\lambda I),
$$

where $\beta_{i}$ and $\beta_{j}^{k}$ are as defined in the proof of Theorem 7. Taking the successive differences then yields the result of Theorem 8 with $\beta>0$ as in the proof of Theorem 7 and with

$$
\zeta \equiv I(\tau-\mu)
$$


i.e.

$$
\zeta=I\left(\frac{\int_{0}^{+\infty} f^{2}(v)[F(v)]^{I-2} d v}{\int_{0}^{+\infty} f(v)[F(v)]^{I-1} d v}-\frac{\int_{0}^{+\infty} v^{2} f^{2}(v)[F(v)]^{I-2} d v}{\int_{0}^{+\infty} v f(v)[F(v)]^{I-1} d v}\right) .
$$

Theorem 9. Suppose that Assumptions A1'-A5 hold and that fundamental productivity differences and cost differences across exporters are small: $z_{1}^{k} \simeq \ldots \simeq z_{I}^{k}$ and $c_{1 j}^{k} \simeq \ldots \simeq c_{I j}^{k}$ for all $j, k$. If we remove country $i_{0}$ 's Ricardian comparative advantage, then:

(1) Counterfactual changes in bilateral trade flows, $x_{i j}^{k}$, satisfy

$$
\widehat{x}_{i j}^{k} \simeq 1+\beta\left[\widehat{z}_{i}^{k}-\frac{1}{I} \sum_{i^{\prime}=1}^{I} \widehat{z}_{i^{\prime}}^{k}\right]
$$

(2) Counterfactual changes in country $i_{0}$ 's welfare, $W_{i_{0}} \equiv \mathrm{w}_{i_{0}} / p_{i_{0}}$, satisfy

$$
\widehat{W}_{i_{0}} \simeq 1+\sum_{k=1}^{K} \sum_{i=1}^{I} \alpha_{i_{0}}^{k} \pi_{i i_{0}}^{k} \widehat{z}_{i}^{k}
$$

Proof of Theorem 9. As before and throughout this proof, we use $\mathrm{w}_{i_{0}}$ as our numeraire in the initial and counterfactual trade equilibrium: $\mathrm{w}_{i_{0}}=\left(\mathrm{w}_{i_{0}}\right)^{\prime}=1$.

1. Counterfactual changes in bilateral trade flows, $x_{i j}^{k}$.

Under the assumptions of Theorem 7, we know from Equation (36) that

$$
\ln x_{i j}^{k} \simeq \beta_{i}+\beta_{j}^{k}+\beta \ln z_{i}^{k}-\beta \ln d_{i j}^{k},
$$

where

$$
\begin{aligned}
\beta_{i} & \equiv \ln \kappa-(\delta I+\sigma-1) \ln \left(\mathrm{w}_{i}\right) \\
\beta_{j}^{k} & \equiv \ln \left(\alpha_{j}^{k} \mathrm{w}_{j} L_{j}\right)+\delta \sum_{i^{\prime}=1}^{I} \ln c_{i^{\prime} j}^{k}-\ln E\left[p_{j}^{k}(\omega)^{1-\sigma}\right] ; \\
\beta & \equiv \delta I+\sigma-1 .
\end{aligned}
$$

Differentiating Equation (44) we obtain

$$
\mathrm{d} \ln x_{i j}^{k} \simeq \mathrm{d} \beta_{i}+\mathrm{d} \beta_{j}^{k}+\beta \mathrm{d} \ln z_{i}^{k}-\beta \mathrm{d} \ln d_{i j}^{k}
$$

Since trade costs are assumed to be constant and productivity levels are adjusted to maintain wages constant in the counterfactual equilibrium, $\mathrm{d} \ln \mathrm{w}_{i}=0$, the previous expression can be simplified as

$$
\mathrm{d} \ln x_{i j}^{k} \simeq \mathrm{d} \beta_{j}^{k}+\beta \mathrm{d} \ln z_{i}^{k} .
$$

Under Assumption A4, we also know that $\mathrm{d} \ln \left(\alpha_{j}^{k} \mathrm{w}_{j} L_{j}\right)=0$. Hence,

$$
\mathrm{d} \ln x_{i j}^{k} \simeq-\delta \sum_{i^{\prime}=1}^{I} \mathrm{~d} \ln z_{i^{\prime} j}^{k}-\mathrm{d} \ln E\left[p_{j}^{k}(\omega)^{1-\sigma}\right]+\beta \mathrm{d} \ln z_{i}^{k} .
$$


Since consumption levels are chosen optimally in the initial equilibrium, the envelope theorem also implies

$$
\mathrm{d} \ln E\left[p_{j}^{k}(\omega)^{1-\sigma}\right]=(1-\sigma) \sum_{i=1}^{I} \pi_{i j}^{k} \mathrm{~d} \ln z_{i}^{k},
$$

which, around $c_{1 j}^{k}=\ldots=c_{I j}^{k}$, gives the following first-order approximation

$$
\mathrm{d} \ln E\left[p_{j}^{k}(\omega)^{1-\sigma}\right] \simeq \frac{(1-\sigma)}{I} \sum_{i=1}^{I} \mathrm{~d} \ln z_{i}^{k} .
$$

Combining Equations (45) and (46) with the definition of $\beta$, we obtain

$$
\mathrm{d} \ln x_{i j}^{k} \simeq \beta\left[\mathrm{d} \ln z_{i}^{k}-\frac{1}{I} \sum_{i^{\prime}=1}^{I} \mathrm{~d} \ln z_{i^{\prime}}^{k}\right],
$$

which can be rearranged as

$$
\widehat{x}_{i j}^{k} \simeq 1+\beta\left[\widehat{z}_{i}^{k}-\frac{1}{I} \sum_{i^{\prime}=1}^{I} \widehat{z}_{i^{\prime}}^{k}\right]
$$

How does the previous expression relate to counterfactual changes in bilateral trade flows derived under Assumptions A1-A4? Let us approximate the counterfactual change in $\widehat{x}_{i j}^{k}$ obtained from Equation (14) by its first order Taylor series around $\widehat{z}_{1}^{k}=\ldots=\widehat{z}_{I}^{k}=1$ and $c_{1 j}^{k}=\ldots=c_{I j}^{k}$. Under the assumptions of Theorem 1, we know that

$$
\widehat{x}_{i j}^{k}=\frac{\left(\widehat{z}_{i}^{k}\right)^{\theta}}{\sum_{i^{\prime}=1}^{I}\left(\widehat{z}_{i^{\prime}}^{k}\right)^{\theta} \pi_{i^{\prime} j}^{k}},
$$

so taking the first-order approximation around $\widehat{z}_{1}^{k}=\ldots=\widehat{z}_{I}^{k}=1$ and $c_{1 j}^{k}=\ldots=c_{I j}^{k}$ gives

$$
\widehat{x}_{i j}^{k} \simeq 1+\theta\left[\widehat{z}_{i}^{k}-\frac{1}{I} \sum_{i^{\prime}=1}^{I} \widehat{z}_{i^{\prime}}^{k}\right] .
$$

Comparing Equations (47) and (48), we see that conditional on the estimate of the elasticity of imports with respect to productivity changes, which can be estimated using cross-sectional data, Equations (5) and (29), the counterfactual predictions for small changes in technology are the same under Assumptions A1 and A1'.

2. Counterfactual changes in country $i_{0}$ 's welfare, $W_{i_{0}} \equiv \mathrm{w}_{i_{0}} / p_{i_{0}}$.

Since consumption levels are chosen optimally in the initial equilibrium, the envelope theorem implies

$$
\mathrm{d} \ln p_{i_{0}}^{k}=-\sum_{\omega \in \Omega} \pi_{i_{0}}^{k}(\omega) \mathrm{d} \ln p_{i_{0}}^{k}(\omega)
$$

where $\pi_{i_{0}}^{k}(\omega)$ is the share of expenditure of variety $\omega$ in country $i_{0}$ and industry $k$. Using Assumption A3, the previous expression can be rearranged as

$$
\mathrm{d} \ln p_{i_{0}}^{k}=-\sum_{i=1}^{I} \pi_{i i_{0}}^{k}\left(\mathrm{~d} \ln z_{i}^{k}+\mathrm{d} \ln \mathrm{w}_{i}\right)
$$


where $\pi_{i i_{0}}^{k}$ is the share of expenditure on varieties from country $i$ in country $i_{0}$ and industry $k$. Since wages are unchanged in the counterfactual equilibrium, $\mathrm{d} \ln \mathrm{w}_{i}=0$, we obtain

$$
\mathrm{d} \ln p_{i_{0}}^{k}=-\sum_{i=1}^{I} \pi_{i i_{0}}^{k} \mathrm{~d} \ln z_{i}^{k}
$$

Combing the previous expression with the fact that the upper-tier utility function is Cobb-Douglas, we get

$$
\mathrm{d} \ln W_{i_{0}}=-\mathrm{d} \ln p_{i_{0}}=\sum_{k=1}^{K} \sum_{i=1}^{I} \alpha_{i_{0}}^{k} \pi_{i i_{0}} \mathrm{~d} \ln z_{i}^{k}
$$

which can be rearranged as

$$
\widehat{W}_{i_{0}} \simeq 1+\sum_{k=1}^{K} \sum_{i=1}^{I} \alpha_{i_{0}}^{k} \pi_{i i_{0}}^{k} \widehat{z}_{i}^{k}
$$

How does the previous expression relate to counterfactual changes in bilateral trade flows derived under Assumptions A1-A4? Again, let us approximate the counterfactual change in $\widehat{W}_{i_{0}}^{k}$ obtained from Equation (14) by its first order Taylor series around $\widehat{z}_{1}^{k}=\ldots=\widehat{z}_{I}^{k}=1$. Under the assumptions of Theorem 5, we know that

$$
\widehat{W}_{i_{0}}=\prod_{k=1}^{K}\left[\sum_{i=1}^{I} \pi_{i i_{0}}^{k}\left(\widehat{z}_{i}^{k}\right)^{-\theta}\right]^{\alpha_{i_{0}}^{k} / \theta} .
$$

Taking the first-order approximation around $\widehat{z}_{1}^{k}=\ldots=\widehat{z}_{I}^{k}=1$ gives

$$
\widehat{W}_{i_{0}} \simeq 1+\sum_{k=1}^{K} \sum_{i=1}^{I} \alpha_{i_{0}}^{k} \pi_{i i_{0}}^{k} \widehat{z}_{i}^{k}
$$

Comparing Equations (49) and (50), we see that the counterfactual changes in welfare associated with small technological changes are the same under Assumptions A1 and A1'. Compared to our counterfactual predictions on bilateral trade flows, note that this result does not rely on the assumptions that cost differences across exporters are small: $c_{1 j}^{k} \simeq \ldots \simeq c_{I j}^{k}$ for all $j$ and $k$. 
Appendix C: Additonal Counterfactual Results

\section{Table A1: Robustness of Counterfactual Results}

\begin{tabular}{lccc}
\hline & \multicolumn{3}{c}{$\begin{array}{c}\text { Outcome variable: \% change in welfare relative } \\
\text { to the total gains from trade }\end{array}$} \\
\cline { 2 - 4 } & $\begin{array}{c}\text { No preference } \\
\text { differences }\end{array}$ & $\begin{array}{c}\text { No trade } \\
\text { costs }\end{array}$ & $\begin{array}{c}\text { No preference } \\
\text { differences or } \\
\text { trade costs }\end{array}$ \\
Reference country: & $(1)$ & $(2)$ & $(3)$ \\
\hline Australia & -41.1 & -46.9 & -57.8 \\
Belgium \& Luxembourg & 0.4 & 0.3 & -8.0 \\
Czech Republic & -3.2 & -10.3 & -20.5 \\
Denmark & -11.7 & -2.2 & -23.3 \\
Spain & -11.6 & -7.7 & -22.9 \\
Finland & -22.6 & 3.3 & -41.8 \\
France & -3.9 & -3.6 & -4.8 \\
Germany & 0.9 & 0.7 & -1.4 \\
Greece & -59.6 & -55.9 & -79.9 \\
Hungary & -2.7 & -10.5 & -14.1 \\
Ireland & -17.6 & -9.1 & -43.4 \\
Italy & -4.7 & 9.7 & -18.0 \\
Japan & 11.7 & 27.2 & -41.7 \\
Korea & -5.8 & -25.3 & -36.9 \\
Netherlands & -7.7 & -2.1 & -12.0 \\
Poland & -26.1 & -27.6 & -36.7 \\
Portugal & -22.9 & -16.3 & -40.1 \\
Slovakia & -3.2 & -8.5 & -29.8 \\
Sweden & -0.9 & -0.4 & -8.8 \\
United Kingdom & -4.4 & -5.4 & -6.7 \\
United States & -10.4 & -21.3 & -24.3 \\
World Average & -11.8 & -10.1 & -27.3 \\
\hline Note & & & \\
\hline
\end{tabular}

Notes: Results from counterfactual calculations in which, one at a time for each country listed (the 'reference country'), every other country in the world is given the reference country's relative productivity levels across industries, while adjusting each country's absolute productivity levels in such a way as to hold nominal wages fixed around the world (so as to neutralize terms-of-trade effects). The methodology follows Lemma 4 and Theorem 5. All columns report the resulting change in w elfare as a percentage of the total gains from trade; a negative number indicates a loss (and a value of -100 means that this loss is equal to that of moving to autarky). The three columns diiffer in the counterfactual scenario considered. Column (1) considers a scenario in which each country has the same tastes. Column (2) considers a scenario in $w$ hich there are no idiosyncratic trade cost differences across countries (that is, trade costs satisfy the restriction in Equation (8)). And Column (3) considers a scenario that combines the scenarios in Columns (1) and (2). See footnote 47 for details. 